\title{
Morphology-Governed Performance of Plasmonic Photocatalysts
}

\author{
Zhishun Wei ${ }^{1, * \mathbb{D}}$, Marcin Janczarek ${ }^{2}$, Kunlei Wang ${ }^{3,4}$, Shuaizhi Zheng ${ }^{5}$ and \\ Ewa Kowalska ${ }^{3, *(D)}$ \\ 1 Hubei Provincial Key Laboratory of Green Materials for Light Industry, Hubei University of Technology, \\ Wuhan 430068, China \\ 2 Institute of Chemical Technology and Engineering, Faculty of Chemical Technology, \\ Poznan University of Technology, 60-965 Poznan, Poland; marcin.janczarek@put.poznan.pl \\ 3 Institute for Catalysis, Hokkaido University, Sapporo 001-0021, Japan; kunlei@cat.hokudai.ac.jp \\ 4 Northwest Research Institute, Co. Ltd. of C.R.E.C., Lanzhou 730000, China \\ 5 Key Laboratory of Low Dimensional Materials and Application Technology of Ministry of Education, \\ School of Materials Science and Engineering, Xiangtan University, Xiangtan 411105, China; \\ xishuai423@hotmail.com \\ * Correspondence: wei.zhishun@hbut.edu.cn (Z.W.); kowalska@cat.hokudai.ac.jp (E.K.)
}

Received: 11 August 2020; Accepted: 12 September 2020; Published: 17 September 2020

check for updates

\begin{abstract}
Plasmonic photocatalysts have been extensively studied for the past decade as a possible solution to energy crisis and environmental problems. Although various reports on plasmonic photocatalysts have been published, including synthesis methods, applications, and mechanism clarifications, the quantum yields of photochemical reactions are usually too low for commercialization. Accordingly, it has been proposed that preparation of plasmonic photocatalysts with efficient light harvesting and inhibition of charge carriers' recombination might result in improvement of photocatalytic activity. Among various strategies, nano-architecture of plasmonic photocatalysts seems to be one of the best strategies, including the design of properties for both semiconductor and noble-metal-deposits, as well as the interactions between them. For example, faceted nanoparticles, nanotubes, aerogels, and super-nano structures of semiconductors have shown the improvement of photocatalytic activity and stability. Moreover, the selective deposition of noble metals on some parts of semiconductor nanostructures (e.g., specific facets, basal or lateral surfaces) results in an activity increase. Additionally, mono-, bi-, and ternary-metal-modifications have been proposed as the other ways of performance improvement. However, in some cases, the interactions between different noble metals might cause unwanted charge carriers' recombination. Accordingly, this review discusses the recent strategies on the improvements of the photocatalytic performance of plasmonic photocatalysts.
\end{abstract}

Keywords: plasmonic photocatalysis; vis-responsive photocatalysts; morphology; faceted particles; nanotubes; gold; silver; copper; platinum

\section{Introduction}

The consumption of fossil fuels has been significantly increasing in recent years because of the fast industry development and world population growth. In the consequence, continuous environmental pollution and shortage of renewable energy resources have become major challenges faced by humanity. Therefore, the development of environment-friendly, clean, safe, and sustainable energy sources is one of the biggest challenges for the whole world. Among all available options, solar energy is one of the most prospective, especially for the developing countries with usually high intensity and duration (daily and yearly) of solar radiation, and serious energy and environmental problems. Accordingly, 
the development of environment-friendly technologies using solar energy is an important and useful way to solve humanity problems.

For example, heterogeneous photocatalysis under solar radiation has been considered as environment-friendly and probable candidate to overcome these challenges [1-4]. In general, photocatalyst (semiconductor) is activated under light irradiation with energy equal to or larger than its bandgap, resulting in transfer of electrons from valence band (VB) to conduction band (CB), thus forming charge carriers, i.e., electrons in $C B$ and holes in VB, as shown in Figure 1a. Charge carriers might either react with some reagents adsorbed on the photocatalyst surface or recombine in the bulk or on the surface, i.e., bulk and surface recombination [5], respectively. The recombination results in an obvious decrease in photocatalytic efficiency, reaching quantum yields much lower than expected 100\%. Accordingly, various methods have been proposed to limit this recombination [6], including properties' improvements, e.g., higher crystallinity, less defects' content, perfect crystal morphology (faceted particles) [7-11], larger content of shallow than deep electron traps (ETs) [12]), and various modifications, e.g., doping [13-15], surface modifications [16-19], heterojunction formation (coupled semiconductors) [20-22]. One of the most efficient methods to inhibit the charge carriers' recombination is the surface modification of photocatalyst with deposits of noble metals, because noble metals work as an electrons' scavenger (Figure 1b) because of larger work function of metals than the electron affinity of oxide semiconductors, as first found for platinum-modified titania almost half century ago by Bard [23].

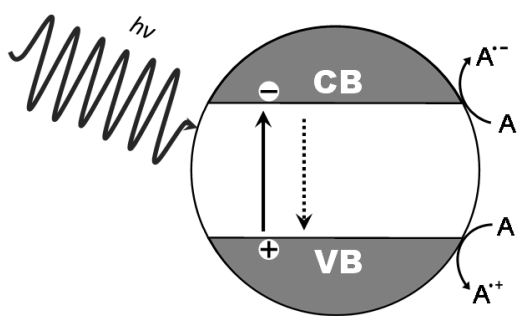

(a)

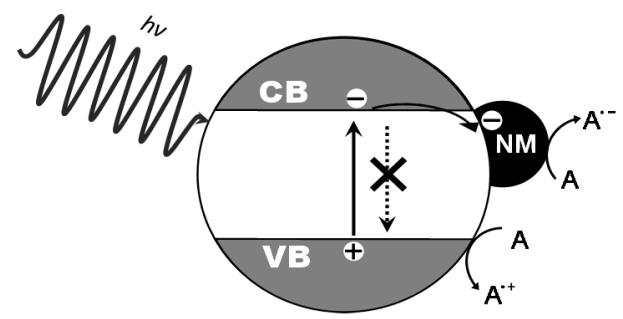

(b)

Figure 1. The schematic drawings of: (a) Semiconductor excitation, charge carriers' formation $(\uparrow)$, and following redox reactions on the semiconductor surface or charge carriers: recombination $(\downarrow)$; and (b) electron scavenging by noble metal (NM) deposits; A-reagent adsorbed on the semiconductor surface; - electron; + hole.

Another problem of heterogeneous photocatalysts is their wide bandgaps (despite being positive for high redox activity), and thus low activity under solar radiation, as they must be excited with UV irradiation, being only ca. $4 \%$ of solar light. Accordingly, various strategies have been proposed to obtain vis-active materials, including also the methods used for the inhibition of charge carriers' recombination, e.g., doping, surface modification, and heterojunction formation [24-28]. Interestingly, noble metals, known for activity enhancement under UV irradiation for many years, have also been found to activate wide-bandgap semiconductors toward vis and even NIR range of solar spectrum, because of plasmonic properties [29-34], and thus noble-metal-modified semiconductors with activity under vis/NIR have been named as plasmonic photocatalysts.

Three main mechanisms of plasmonic photocatalysis have been considered, i.e., energy transfer (Figure 2a), electron transfer (Figure 2b) and plasmonic heating. Moreover, the light scattering on the deposits of noble metals has been proposed to enhance the overall photocatalytic performance by efficient light harvesting. In the case of energy transfer, the respective energy levels should overlap, and thus more probable is energy transfer for $\mathrm{Ag} / \mathrm{TiO}_{2}$ with similar energies, i.e., ca. 2.8-3.0 for $\mathrm{Ag}$ deposits (depending on the shape and size) and 3.0-3.2 eV for titania than that for $\mathrm{Au} / \mathrm{TiO}_{2}$ with much different energy of gold localized surface plasmon resonance (LSPR; ca. 2.2-2.5 eV for spherical Au NPs) than that of titania. Therefore, only pre-modified titania with vis-response has been reported as 
able for energy transfer from Au excitation, e.g., titania modified with nitrogen [35] and defect-rich titania, i.e., with crystal defects [36] and amorphous titania with disorders-the localized states inside bandgap [37].

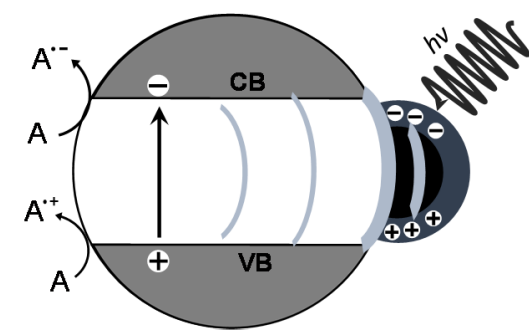

(a)

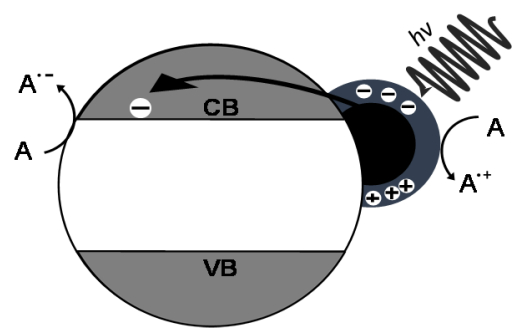

(b)

Figure 2. The schematic drawings of the proposed mechanism of plasmonic photocatalysis: (a) energy transfer, and (b) electron transfer; A-reagent adsorbed on the semiconductor surface.

In the case of electron transfer, noble metals work as sensitizers (being even named as "plasmonic sensitizers"), and thus "hot" electron transfer from noble metal to CB of semiconductor has been proposed as the first step of plasmonic photocatalysis [30]. Next, the surface reactions between "hot" electrons and adsorbed species are considered to take place on the semiconductor surface, e.g., with molecular oxygen, resulting in the formation of reactive oxygen species (ROS). At the same time, to keep noble metal at zero-valent state, oxidation of some compounds on the surface of electron-deficient noble metal must proceed [38]. Although, there are no direct proof for electron transfer (as detected electrons might also origin from energy transfer in some cases), there are many studies suggesting this mechanism as the most probable via various experimental approaches, including femtosecond transient absorption spectroscopy (electrons transferred from $\mathrm{Au}$ to $\mathrm{TiO}_{2}$ ) [39,40], EPR spectroscopy (different oxidation species under UV and vis irradiation) [41,42], time-resolved microwave conductivity (TRMC) method (conductivity under vis irradiation only for titania modified with noble metals: Au [43] and Ag [44]), electrochemical study (shift of electrode potential to negative or positive values and generation of anodic or cathodic photocurrent depending on electrode configuration, i.e., ITO/ $\mathrm{TiO}_{2} / \mathrm{Au}$ or ITO/Au/ $\mathrm{TiO}_{2}$, respectively, as shown in Figure 3) [45].

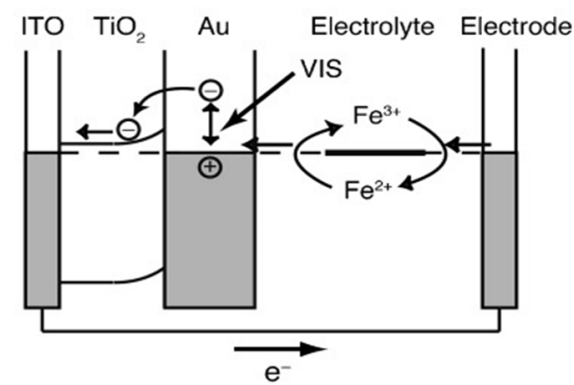

(a)

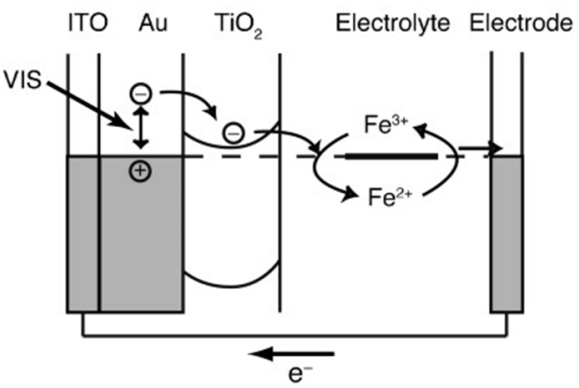

(b)

Figure 3. The schematic drawings of the photoelectrochemical cell with: (a) an $\mathrm{ITO} / \mathrm{TiO}_{2} / \mathrm{Au}$ electrode; and (b) an $\mathrm{ITO} / \mathrm{Au} / \mathrm{TiO}_{2}$ electrode; adapted from [45]. Copyright 2009 Wiley.

The plasmonic heating has also been proposed as the main mechanism of some reactions, i.e., local heating around noble-metal-deposits resulting in the cleavage of some chemical bonds [46]. The mechanism might depend on the semiconductor type. For example, both $\mathrm{Au} / \mathrm{TiO}_{2}$ and $\mathrm{Au} / \mathrm{ZnO}$ are active under vis irradiation, but only $\mathrm{Au} / \mathrm{ZnO}$ is active during heating in the dark [32,47]. Accordingly, plasmon-assisted photocatalysis and plasmon-assisted catalysis (plasmonic heating) might be expected for $\mathrm{Au} / \mathrm{TiO}_{2}$ and $\mathrm{Au} / \mathrm{ZnO}$, respectively. Although some studies have proposed plasmonic heating as the main mechanism of plasmonic photocatalysis [46-49], plenty of reports have rejected this possibility, 
because of the inactivity of noble-modified insulators or unsupported noble-metals in comparison to highly active noble-metal-modified semiconductors [31,36,50-53]. Moreover, studies on activation energy have also excluded plasmonic heating as the main mechanism for photocurrent generation [34] and decomposition of organic compounds [54].

Although the final mechanism has not been clarified yet, and might depend on the properties/morphology/composition of the photocatalysts and studied reactions, it has been proven that plasmonic photocatalysts are active for various photocatalytic reactions under vis range of solar spectrum, e.g., solar energy conversion (into electricity [45] and fuels [55]), degradation of organic compounds [56] and microorganisms [57], synthesis of organic compounds [58], and cancer treatment [59]. However, the overall activity is usually much lower than that under UV, and thus various procedures have been proposed to improve the photocatalytic performance. Among these methods, the nanoarchitecture of morphology has been proposed as efficient one for activity enhancement, as discussed in the next sections.

\section{Morphology Design of Plasmonic Photocatalysts}

The most typical plasmonic photocatalysts (like all other heterogeneous photocatalysts) are semiconductors in the form of particles (nano or micro) with deposits of noble metals (usually in the form of NPs). In the case of these photocatalysts, the activity under vis irradiation is mainly governed by the properties of noble-metal deposits. Accordingly, it has been proposed that higher polydispersity of noble metals (both in the size and the shape) results in higher photocatalytic activity as a result of efficient light harvesting [38,56,60], i.e., different size/shape of noble metal causes the absorption of photons with different energy, as LSPR depends on the properties of noble metals (longer wavelengths for larger NPs and with more complex morphology than spherical NPs). Although usually particles of semiconductors are highly polydisperse (in both composition and the particles' morphology), even for commercial and famous photocatalysts, e.g., titania P25 (anatase/rutile/amorphous phases) [61], the morphology-controlled particles have also been used for photocatalysis. Among these particles, faceted ones, i.e., with well-observed crystalline facets, have recently been intensively studied because of high photocatalytic activities $[8,9,62-66]$. Obviously, faceted particles have also been used as supports for noble-metal deposits, as shortly discussed below.

\subsection{Faceted Semiconductors as Supports for Noble Metals}

The most famous faceted titania photocatalysts are anatase particles of either octahedral (same as anatase crystals in nature) or decahedral shapes, i.e., with eight equivalent $\{101\}$ facets or eight $\{101\}$ facets and two additional $\{001\}$ facets on the top/bottom of anatase crystal, respectively $[8,10-12,62,63,65-68]$. Additionally, other faceted materials have also been investigated, such as rutile [69,70] and brookite [71] titania, iridium [72], $\mathrm{AgNbO}_{3}$ [73], $\mathrm{TiOF}_{2}$ [74], $\mathrm{MgAl}_{2} \mathrm{O}_{4}$ [75], $\mathrm{BiOBr}$ [76], $\mathrm{BiOCl}$ [77,78], $\mathrm{Ag}_{2} \mathrm{MO}_{4}$ [79], $\mathrm{BiVO}_{4}$ [80], $\mathrm{ZnO}$ [81], and $\mathrm{Cu}_{2} \mathrm{WS}_{4}$ [82]. Since faceted photocatalysts show usually much higher activity than other particles of irregular shape, they have been proposed for various applications in the photocatalysis field, including also plasmonic photocatalysis. One of the first reports on faceted plasmonic photocatalysts have been shown by Janczarek et al. for decahedral anatase particles (DAP) modified with mono- and bi-metal NPs of silver and copper by photodeposition method, i.e., under UV irradiation in the presence of methanol as hole scavenger and in the absence of oxygen to avoid capture of electrons (being main reducer for respective metal cations) [83]. It has been found that the sequence of metal deposition on DAP has been detrimental for the resultant properties (Figure 4), and thus final activities. For example, in the case of sequential deposition, the second metal is also deposited on the surface of the first deposited metal since under UV irradiation, photogenerated electrons are scavenged by the first metal, and thus the electron-rich metal is attractive for cations' adsorption of second metal (Figure 4c,d). Accordingly, in the case of bi-metal samples prepared by sequential deposition both monometallic and bi-metallic deposits are obtained. In contrast, in the case of co-deposition, the competition between metals for photogenerated electrons 
results in the formation of fine NPs of $\mathrm{Cu}$ and large NPs of Ag (Figure 4b). Although, all samples show high enhancement of photocatalytic activity under UV irradiation (3-4× than that by bare DAP), only sample with mono-metallic silver exhibits high activity under vis irradiation ( $>455 \mathrm{~nm}$ ), probably since only this sample keeps plasmonic properties as copper is easily oxidized in air than silver.

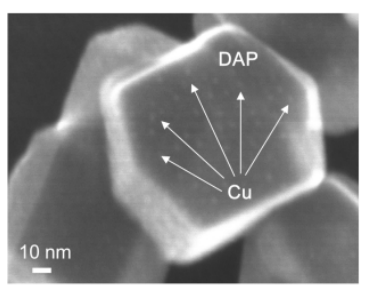

(a)

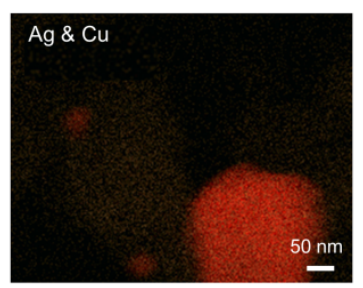

(b)

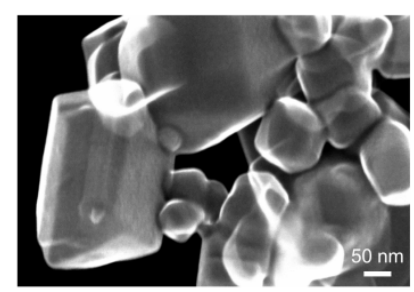

(c)

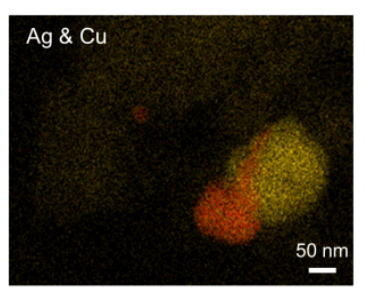

(d)

Figure 4. SEM (a,c) and EDS (b,d) images of: (a) decahedral anatase particles (DAP) with monometallic $\mathrm{Cu}$, (b) DAP with large Ag NPs and fine Cu NPs, prepared by co-deposition, (c,d) DAP with bimetallic deposits prepared by deposition of $\mathrm{Cu}$ on $\mathrm{Ag} / \mathrm{DAP}$; red-Ag, yellow-Cu; adapted with permission from [83]. Copyright 2017 Creative Commons Attribution.

These findings have been confirmed with another faceted anatase sample, i.e., octahedral anatase particles (OAP) with eight equivalent (101) facets by Wei et al. [84]. It is found that vis activity decreases in the following order: $\mathrm{Au} / \mathrm{OAP}>\mathrm{Ag} / \mathrm{OAP}>\mathrm{Cu} / \mathrm{OAP}$, correlating with the content of zero-valent state of noble metals. Next, $\mathrm{Au} / \mathrm{OAP}$ samples with different sizes of Au NPs are investigated by changing the photodeposition conditions, i.e., from anaerobic (usually used) to initially aerobic and from methanol to 2-propanol (as hole scavenger) [85]. Interestingly, it is found that an increase in the size of Au NPs results in an increase in the photocatalytic activity under vis irradiation, probably because of larger areas with field enhancement, as shown in Figure 5.

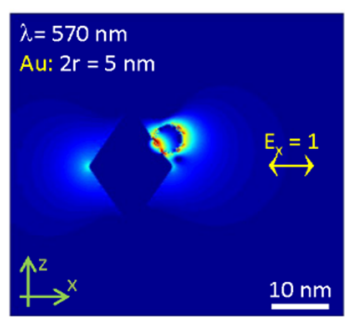

(a)

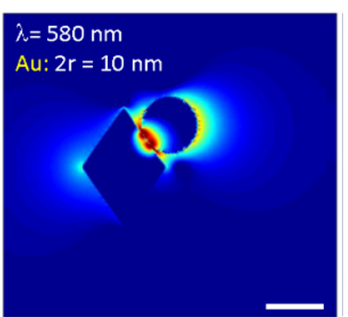

(b)

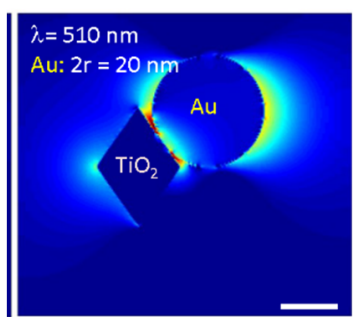

(c)

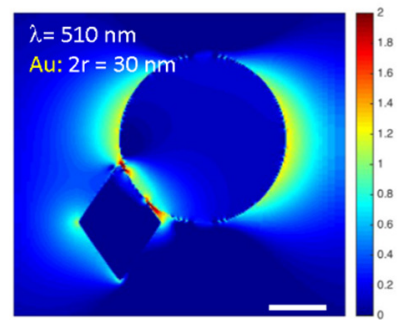

(d)

Figure 5. Simulated light intensity enhancement for different size of Au NPs on OAP, i.e., gold NPs diameter of: (a) $5 \mathrm{~nm},(\mathbf{b}) 10 \mathrm{~nm}$, (c) $20 \mathrm{~nm}$, and (d) $30 \mathrm{~nm}$. The intensity color map is logarithmic and shows up to $10^{2}$ times enhancement localized mainly at the interface between gold and titania; the same scale for all images; adapted with permission from [85]. Copyright 2017 Creative Commons Attribution.

Similar findings have been obtained for Ag-modified OAP samples, i.e., an increase in the activity with an increase in the size of Ag NPs [44]. Moreover, the participation of the mobile electrons in the mechanism of 2-propanol oxidation under vis irradiation has been confirmed by time-resolved microwave conductivity (TRMC). The decay of TRMC signal correlates with the activity, suggesting that more "hot" electrons are formed in the case of larger Ag deposits, as shown in Figure 6.

The continuation of these studies results in the comparison between noble-metal-modified DAP and OAP [86]. It should be pointed out that DAP shows the highest photocatalytic activity among various titania samples (commercial and self-synthesized, including OAP) despite not having the best surface properties (specific surface area of only ca. $5-20 \mathrm{~m}^{2} \mathrm{~g}^{-1}$ [10]), because of intrinsic properties of two-kind facets, i.e., the natural separation of charge carriers when electrons migrate to (101), whereas holes to (001) facets [63]. Indeed, under UV irradiation DAP samples (bare and modified with NPs of $\mathrm{Ag}, \mathrm{Cu}$, and $\mathrm{Au}$ ) show higher activity than that by respective OAP samples. However, 
the opposite trend has been observed under vis irradiation where OAP samples are more active than DAP ones. Interestingly, the comparison between faceted and commercial titania samples shows that $\mathrm{Au} / \mathrm{OAP}$ exhibits ca. one order in magnitude higher activity than that by Au-modified commercial titania samples (of similar properties; Figure 7a), suggesting fast charge carriers' separation (Figure 7b), which is quite reasonable considering the preferential distribution of shallow than deep electron traps (ETs) in OAP [12]. In contrast, Au/DAP shows the worst performance among 16 tested samples, possibly because of intrinsic properties of DAP (as discussed above), i.e., back electron transfer to (101) facets $\left(\mathrm{Au} \rightarrow \mathrm{TiO}_{2}(101) \rightarrow \mathrm{Au}\right)$, as gold is mainly deposited on these facets, as shown in Figure 7c.

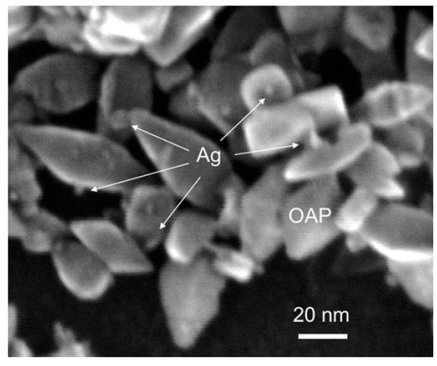

(a)

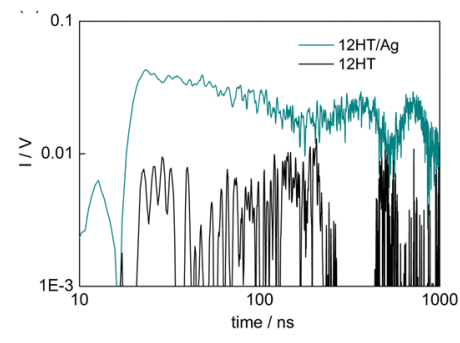

(b)

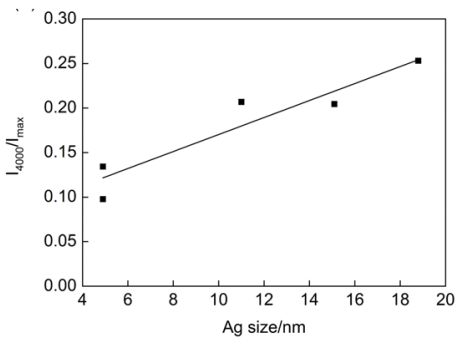

(c)

Figure 6. Characteristics of Ag/OAP samples: (a) SEM image, (b) time-resolved microwave conductivity (TRMC) signal (OAP-12HT; Ag/OAP-12HT/Ag). (c) The correlation between the decay of TRMC signal and the size of Ag NPs; adapted with permission from [44]. Copyright 2018 Creative Commons Attribution.

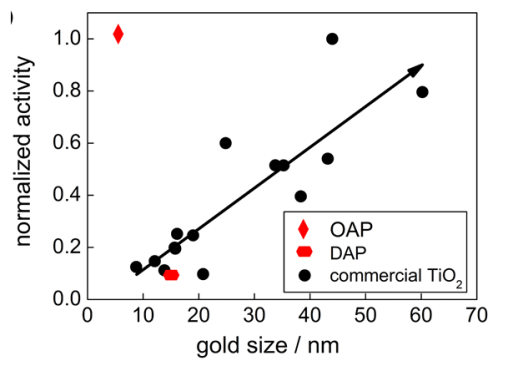

(a)

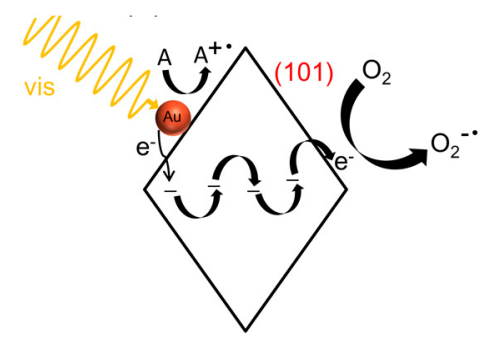

(b)

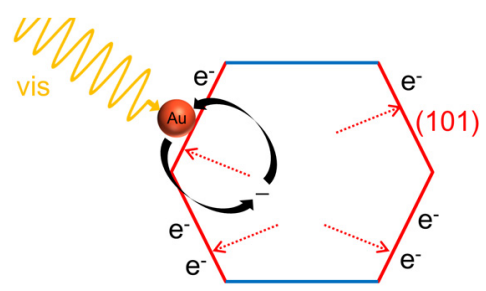

(c)

Figure 7. (a) The comparison of vis activity of Au-modified commercial titania samples with that by $\mathrm{Au} / \mathrm{OAP}$ and $\mathrm{Au} / \mathrm{DAP}$, and $(\mathbf{b}, \mathbf{c})$ the schematic drawings of possible electron transfer/recombination under vis excitation for: (b) Au/OAP and (c) Au/DAP; adapted with permission from [86]. Copyright 2018 Creative Commons Attribution.

Interestingly, quite different performance has been observed against microorganisms, where $\mathrm{Cu} / \mathrm{DAP}$ exhibits much higher activity than $\mathrm{Cu} / \mathrm{OAP}$ under vis irradiation, probably because of larger content of positively charged $\mathrm{Cu}$ [87]. It should be pointed out that for antimicrobial action, positively charged noble metals are much more active than zero-valent ones, because of both intrinsic action of noble-metal cations (in dark) and easier adsorption on negatively charged bacteria [88]. Accordingly, $\mathrm{Ag} / \mathrm{TiO} \mathrm{O}_{2}$ and $\mathrm{Cu} / \mathrm{TiO}_{2}$ are usually much more active than $\mathrm{Au} / \mathrm{TiO}_{2}$ and $\mathrm{Pt} / \mathrm{TiO}_{2}$ samples. Indeed, only $\mathrm{Cu}$ - and Ag-modified DAP and OAP show higher activity under vis than that in the dark [87]. Moreover, a decrease in activity is observed under UV irradiation, which should be caused by opposite direction of electron transfer (from $\mathrm{TiO}_{2}$ to noble metal), resulting in negatively charged noble metal, and thus causing a repulsion between noble metal and bacteria.

Other groups have also intensively studied plasmonic photocatalysts using faceted semiconductors. For example, Mao et al. have obtained Pt-modified DAP samples, and tested them for photocatalytic $\mathrm{CO}_{2}$ reduction [89]. It has been shown that without Pt-loading, $\{010\}$ facets adsorb more $\mathrm{CO}_{2}$ 
molecules, showing longer lifetime of photogenerated charges than $\{001\}$ facets, and thus causing higher photocatalytic activity. Interestingly, the presence of small Pt NPs loaded on $\{010\}$ facets enhances the separation of photogenerated carriers more efficiency than Pt particles (aggregates) deposited on $\{001\}$ facets. Unfortunately, the study has been performed only under UV irradiation, and thus strong plasmonic effect is not expected. In another work [90], DAP has been modified with Pt NPs by different methods and platinum precursors, which influences the size, distribution, and chemical states of platinum deposits. For example, photodeposition method results in facet-selective deposition, because of photo-driven spatial separation of photogenerated charges (as discussed above). The selective deposition of Pt NPs is also attributed to adsorption behavior of the metal precursors on different crystal facets. The uniform deposition of $\mathrm{Pt}$ on $\{101\}$ facets by chemical reduction of $\mathrm{H}_{2} \mathrm{PtCl}_{6}$ precursor (different than that for $\mathrm{Pt}\left(\mathrm{NH}_{3}\right)_{4} \mathrm{Cl}_{2}$ ) might be explained by the good adsorption of $\mathrm{PtCl}_{6}{ }^{2-}$ ions on the $\{101\}$ facets. The adsorption of $\mathrm{Pt}\left(\mathrm{NH}_{3}\right)_{4}{ }^{2+}$ is weaker, causing the phenomenon that platinum particles reduced from $\mathrm{Pt}\left(\mathrm{NH}_{3}\right)_{4}{ }^{2+}$ are agglomerated easily before being deposited on the titania facets. Moreover, Kobayashi et al. have shown that adsorption of noble metals on DAP facets depends on the surface charges and $\mathrm{pH}$ value of the reaction mixture [91].

Similar issue has been examined by Zielinska-Jurek et al. where Pt NPs have been deposited on DAP by different methods [92]. The selective deposition of Pt NPs on DAP results from the fact that the surface of $\{101\}$ facets is electron-rich, whereas the oxidized $\{001\}$ surface is electron-deficient. Therefore, Pt NPs are deposited preferably on $\{101\}$ facets with oxygen vacancies. This phenomenon occurs in the case of thermal reduction method-electrons located on the oxygen vacancy states are released, reducing the adsorbed platinum ions. In the case of chemical reduction method (with $\mathrm{NaBH}_{4}$ ), a solution-dominated reduction pathway promotes the mechanism of seed-mediated growth of $\mathrm{Pt}$ deposits on titania facets (Figure 8). The surface of seeds simultaneously acts as both deposition and reduction site, which influences further growth of Pt NPs and causes the formation of larger particles. In contrast to OAP and commercial titania samples modified with noble metals by photodeposition, it has been found that a decrease in the size of Pt NPs results in activity enhancement under both UV and vis irradiation.

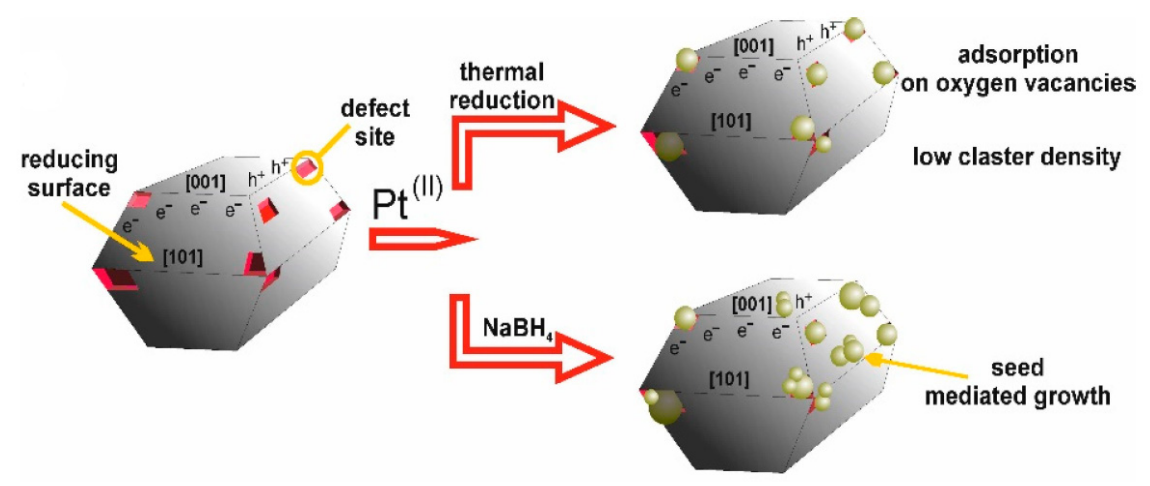

Figure 8. Proposed mechanism of Pt NPs deposition on DAPs; adapted with permission from [92]. Copyright 2019 Creative Commons Attribution.

Application of noble metals to faceted anatase particles might be performed also as a metal-metal alloy to improve the photocatalytic performance, e.g., selective photoconversion of $\mathrm{CO}_{2}$ into hydrocarbons. For example, Au-Pd alloys, deposited selectively on $\{101\}$ facets of DAP, have solved the problem of desorption of reaction intermediates (such as CO molecules) [93]. Moreover, the adjustment of the stoichiometric ratio between $\mathrm{Au}$ and $\mathrm{Pd}$ allows to change the selectivity of the reaction, i.e., $\mathrm{CO} /$ hydrocarbons ratio. However, those studies have been performed also only under UV irradiation, and thus could not be considered as plasmonic photocatalysis.

Interesting work about interactions between Ag NPs and different facets of rutile photoanodes has been performed by Ballestas-Barrientos et al. [70]. The special combination of experimental techniques: SEM and electron backscatter diffraction (EBSD) detector with electrochemical impendence 
spectroscopy has been applied to determine the phenomenon of the Ag NPs photodeposition on the grain boundary defects of preferentially oriented $\{100\}$ rutile nanorod films. Accordingly, it has been reported that the presence of grain boundary defects results in larger Schottky barriers and better charge carrier separation efficiency and is beneficial for the "plasmonic enhancement" during water splitting. However, similar to other studies, UV light has not been excluded (solar simulator), and thus titania excitation should be considered as the main mechanism of action rather than plasmonic photocatalysis. There are many interesting reports on noble-metal modified faceted semiconductors but tested only under UV/vis irradiation [71,82], and thus not further discussed in this review on plasmonic photocatalysis (activity under vis due to LSPR).

The promising strategy for design of plasmonic photocatalysts based on faceted supports is the composition of coupled systems. For example, Bian et al. prepared $\mathrm{Au} / \mathrm{TiO}_{2} / \mathrm{BiVO}_{4}$ plasmonic nanocomposites, at the first stage from $\mathrm{BiVO}_{4} 2 \mathrm{D}$-structured nanoflakes via ion exchange process from $\mathrm{BiOCl}$ nanosheets, followed by coupling (001) facet exposed anatase 2D-structured nanosheets and finally modified with Au nanorods [94]. The important issue of this study is to match different components of nanocomposite for the construction of effective heterojunction system. The $\{001\}$ facet-exposed $\mathrm{TiO}_{2}$ is considered as an efficient acceptor of photogenerated electrons from $\mathrm{BiVO}_{4}$ nanoflakes and plasmonic Au nanorods. The proposed system has been active for photocatalytic $\mathrm{CO}_{2}$ conversion ensuring wide visible-light response in the range from $400 \mathrm{~nm}$ to $660 \mathrm{~nm}(78.9 \%$ of whole visible light spectrum).

\subsection{Other Particulate Plasmonic Photocatalysts with Advanced Morphology}

Besides mono-metallic plasmonic photocatalysts, multi-metallic plasmonic photocatalysts have also been investigated, including bi- (many examples [60,83,95-97]) and tri- [98] metal-modified semiconductors. It has been suggested that preparation of multi-metallic plasmonic photocatalysts should result in enhanced activity because of efficient light harvesting, as the position of LSPR band depends on the kind of noble metal. Indeed, high enhancement of activity has been observed in some cases [95], but other reports suggest that second metal causes charge carriers' recombination instead of separation. For example, in the case of titania modification with Ag and Au, only samples with mono-metallic deposits (Ag NPs and Au NPs deposited separately on the support) show enhanced activity, whereas bi-metallic deposits (e.g., core-shell NPs) causes a decrease in the activity (Figure 9a) [97]. Interestingly, strong field enhancement has been observed for core-shell NPs (Figure $9 b-d$ ), and thus obtained data indirectly support the mechanism of charge transfer rather than energy transfer of plasmonic photocatalysis since enhanced field should cause an activity enhancement (in contrast to experimental results) in the case of energy transfer.

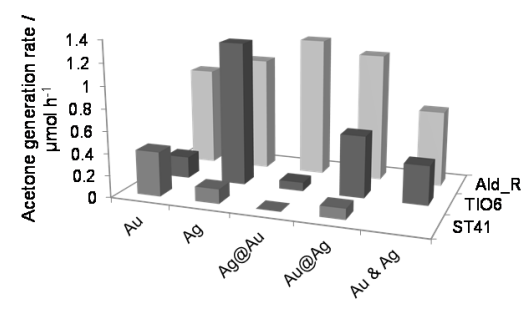

(a)

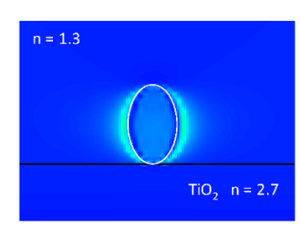

(b)

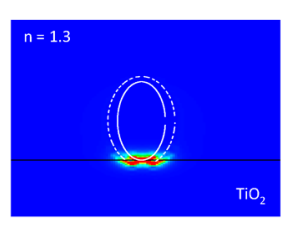

(c)

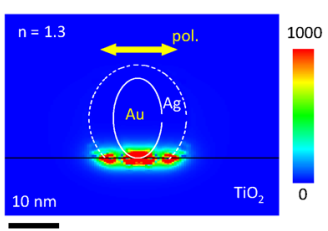

(d)

Figure 9. (a) The comparison of photocatalytic activities of mono- and bi-metal modified commercial titania samples (Ald_R-large rutile particles; TIO6-fine rutile NPs; ST41-large anatase NPs; Ag@Au/Ald_R and Au@Ag/Ald_R samples with separately deposited Ag NPs and Au NPs.); (b-d) The cross-sectional patterns of the near-field intensity enhancement factor of mono- $\left(\mathrm{Au} / \mathrm{TiO}_{2}\right)(\mathbf{b})$ and bi- $\left(\mathrm{Ag} / \mathrm{Au} / \mathrm{TiO}_{2}\right)(\mathbf{c}, \mathbf{d})$ metallic samples; for: $(\mathbf{b}) \mathrm{t}=0$ at $510 \mathrm{~nm}$ wavelength; $(\mathbf{c}) \mathrm{t}=2 \mathrm{~nm}$ at $600 \mathrm{~nm}$, (d) $\mathrm{t}=5 \mathrm{~nm}$ at $570 \mathrm{~nm}$; $\mathrm{t}$-width of silver layer on gold NP; adapted with permission from [97]. Copyrights 2014 Elsevier. 
Titania aerogels modified with NPs of noble metals (gold and copper) have also been proposed as efficient plasmonic photocatalysts [99-101]. Interestingly, it has been found that the localization of gold is decisive for the resultant photocatalytic activity, i.e., the photocatalyst with gold NPs incorporated inside titania network exhibits much higher activity under vis irradiation than that with gold NPs deposited in the porosity, as shown in Figure 10. Although, authors suggest that both mechanisms, i.e., energy and electron transfer, are possible, it seems that such large difference in the vis activity might support the mechanism of electron transfer since the larger interface between titania and gold should facilitate charge migration, whereas same energy transfer (if any) would be expected for similar structures (with similar physicochemical properties) [100]. Moreover, incorporation of less noble metals inside titania aerogel network might also stabilize them against oxidation in air, as plasmonic photocatalysts with zero-valent copper incorporated inside titania aerogel network has been successfully prepared [99].

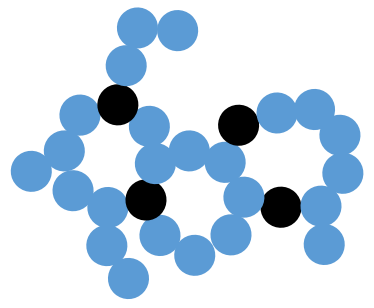

high vis activity

(a)

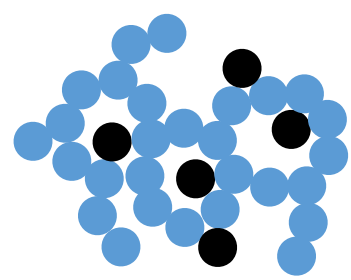

Iow vis activity

(b)

Figure 10. The schematic drawings showing titania aerogels (blue color) with Au NPs (black color): (a) Au NPs incorporated inside titania network, and (b) Au NPs deposited in the porosity; drawn based on [100].

Janus particles have also been proposed as efficient plasmonic photocatalyst for hydrogen evolution under vis irradiation [37]. It has been shown that Janus particles composed of amorphous titania (one site) and 50-nm Au NPs (another site) possess much higher activity than respective core $(\mathrm{Au})$-shell( $\left(\mathrm{TiO}_{2}\right) \mathrm{NPs}$, because of strong localization of LSPR at the interface between $\mathrm{Au}$ and $\mathrm{TiO}_{2}$, as shown in Figure 11 (white area). The vis activities $\left(>400 \mathrm{~nm}\right.$ ) of core/shell NPs, bare $\mathrm{TiO}_{2}$ and bare $\mathrm{Au}$ NPs has been much lower than that by Janus particles, reaching only $58 \%, 1 \%$, and $<<1 \%$, respectively.

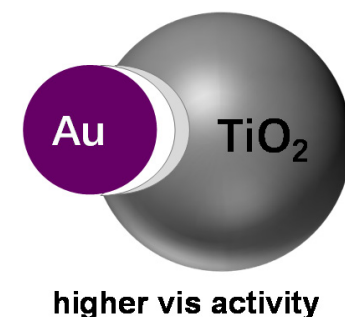

(a)

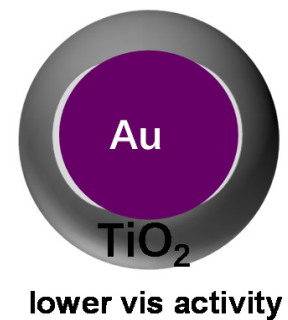

(b)

Figure 11. The schematic drawings of: (a) Janus particle, and (b) core/shell particles; violet-Au; grey- $\mathrm{TiO}_{2}$; white/l. grey-plasmonic near-field distribution; drawn based on [37].

Although, usually noble metals are deposited on the surface of semiconductors, the reverse structures have been investigated. For example, Horiguchi et al. have proposed Au nanorods (NRs) covered with silver layer and then with $\mathrm{TiO}_{2}$ [102]. Interestingly, it has been thought that predominant mechanism might change depending on the width of titania layer, i.e., from electron transfer to energy transfer with an increase in the width, as shown in Figure 12. The electron transfer for the structure with a thin titania layer $(<10 \mathrm{~nm})$ has been proposed because the release of silver cations has been 
observed (silver oxidation after "hot" electron transfer to titania). However, energy transfer has been suggested for broader titania layers $(>10 \mathrm{~nm})$ because the best photocatalytic activity has been obtained for the optimal width of titania layer $(10 \mathrm{~nm})$. The concept of optimal titania layer has been suggested as inconsistent with an electron transfer mechanism since an increase in titania width might result in activity decrease (high probability of electrons' trapping before their arrival at the photocatalyst surface).

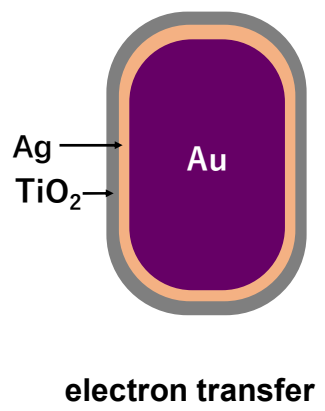

(a)

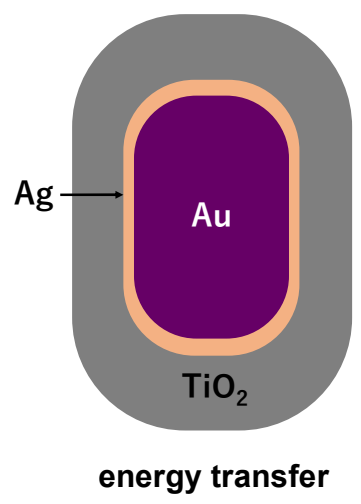

(b)

Figure 12. The schematic drawings showing tri-layered photocatalyst composed of Au NR as a core, silver as an interlayer and $\mathrm{TiO}_{2}$ as a shell with: (a) a thin titania layer with the mechanism of an electron transfer, and (b) a thick titania layer with the mechanism of an energy transfer; drawn based on [102].

Interesting approach has been proposed by Bielan et al. for plasmonic photocatalysts $\left(\mathrm{TiO}_{2}\right.$ with $\mathrm{Pt}$ and $\left.\mathrm{Cu} / \mathrm{Cu}_{\mathrm{x}} \mathrm{O}\right)$ supported on magnetic core for easy separation of photocatalyst after reaction (Figure 13) [103,104]. The photocatalysts exhibit good reusability with almost same reaction rate for fresh and reused (after recovery by a magnet) photocatalysts during consequent photocatalytic cycles. Although, Pt-modified titania samples show vis activity due to LSPR, the magnetic photocatalysts lose the vis response, probably because of "hot" electron trapping by magnetic core $\left(\mathrm{Pt} \rightarrow \mathrm{TiO}_{2} \rightarrow \mathrm{Fe}_{3} \mathrm{O}_{4} / \mathrm{SiO}_{2}\right)$ [103], similarly as suggested for bimetallic [97] and hybrid (co-modified with ruthenium dye [105-107]) plasmonic photocatalysts. Interestingly, self-doped titania (titania with defects) significantly improves the photocatalytic activity under vis irradiation for both supported (on magnetic core) and unsupported plasmonic photocatalysts [104].

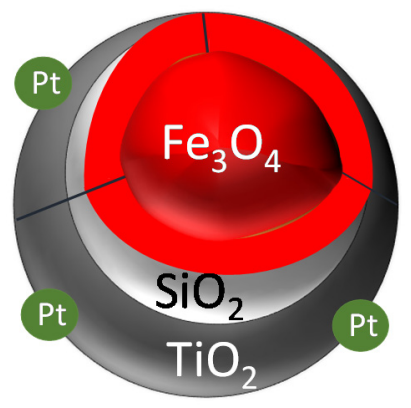

(a)

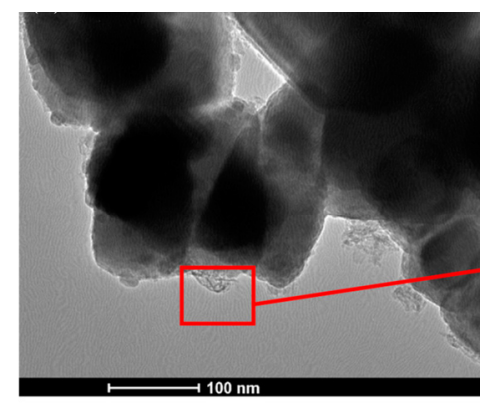

(b)

Figure 13. Pt-modified core $\left(\mathrm{Fe}_{3} \mathrm{O}_{4}\right) /$ interlayer $\left(\mathrm{SiO}_{2}\right) /$ shell $\left(\mathrm{TiO}_{2}\right)$ photocatalysts magnetically separable and recyclable: (a) the schematic drawing; and (b) TEM image (Pt NP in red rectangle); adapted from [104]. Copyright 2020 Creative Commons Attribution.

\subsection{One-Dimensional Plasmonic Photocatalysts}

One-dimensional nanomaterials are considered as ideal candidates for direct transport of electrons because of their orientation characteristics along a certain direction, such as nanowires, nanofibers, 
nanotubes, nanorods, nanobelts, and so on. Obviously, they have also been applied as a support for noble metals to obtained plasmonic photocatalysts.

Similar to faceted plasmonic photocatalysts (discussed in Section 2.1.), the size and distribution of noble-metal NPs on the 1D titania is also important. Accordingly, uniform distribution of Ag NPs on one-dimensional anatase titania results in fast decomposition of 2,4-dichlorophenol under vis irradiation and high reusability (almost same activity after 10 cycles) [108].

Bimetallic NPs have also been applied on 1D titania structures. For example, titania nanowires (TNWs) have been modified with Au/Ag alloyed NPs by a facile hydrothermal and photodeposition method [109]. The synergistic effect between $\mathrm{Au}$ and $\mathrm{Ag}$ has been obtained for selective $\mathrm{CO}_{2}$ reduction with $\mathrm{H}_{2}$ to $\mathrm{CO}$ and hydrocarbons under vis irradiation. Interestingly, it has been proposed that bimetallic deposits might have double function, i.e., as a plasmonic sensitizer (under vis excitation) and as an electron sink (same as under UV irradiation), as shown in Figure 14, and thus charge carriers' recombination (main shortcoming of plasmonic photocatalysis) might be hindered.

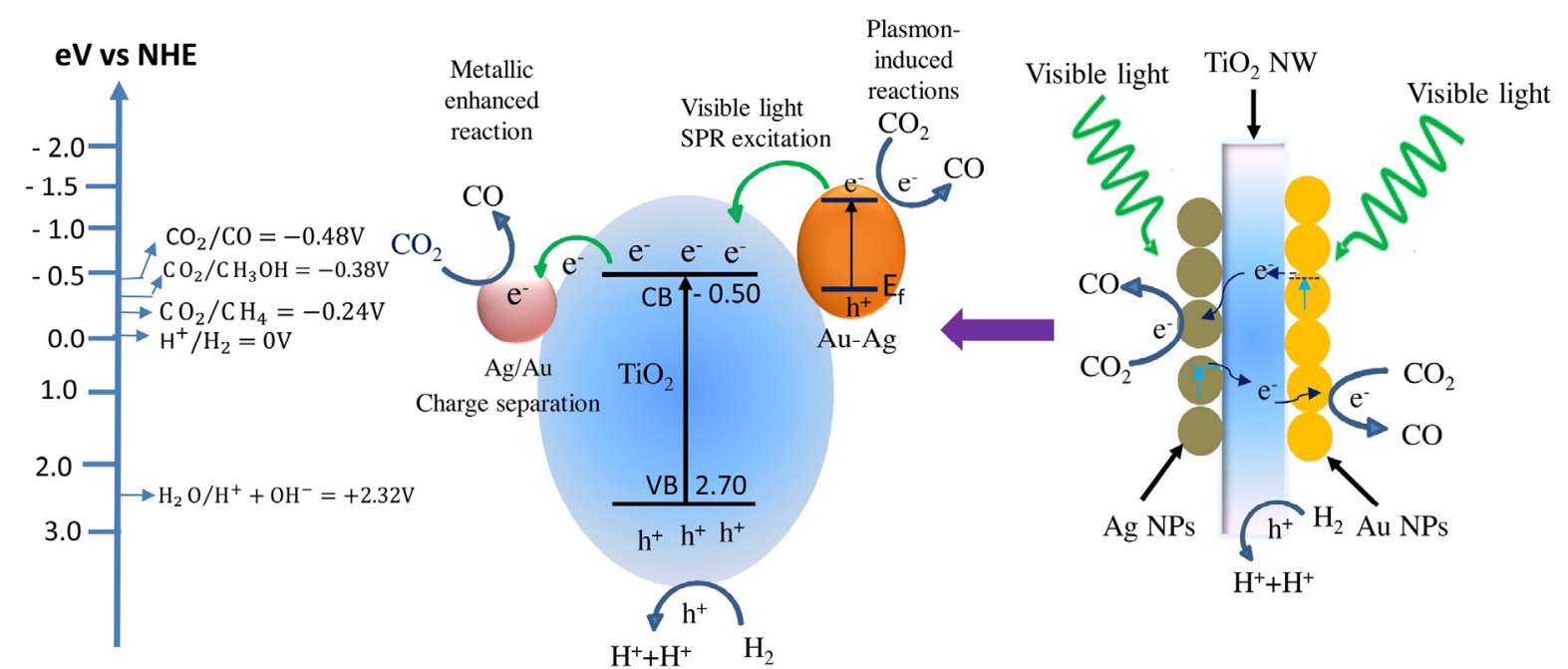

Figure 14. Proposed mechanism showing a photocatalytic process for $\mathrm{CO}_{2}$ reduction by $\mathrm{H}_{2}$ to $\mathrm{CO}$ on $\mathrm{Au} / \mathrm{Ag}-\mathrm{NPs} / \mathrm{TiO}_{2} \mathrm{NWs}$ under vis irradiation; adapted with permission from [109]. Copyrights 2017 Elsevier.

Another structure using 1D titania has been proposed by Nasir et al. in which branched titania (Figure 15a) has been coupled with g- $\mathrm{C}_{3} \mathrm{~N}_{4}$ quantum dots (QDs) and surface modified with Au NPs [110]. The composite has exhibited very high quantum efficiency $(19.5 \%)$ for hydrogen generation under vis irradiation (420 nm). It has been proposed that both Au NPs and g- $\mathrm{C}_{3} \mathrm{~N}_{4}$ QDs might absorb visible light, resulting in an electron transfer to CB of titania, as shown in Figure 15. However, another possibility should be also considered, i.e., an electron transfer from $\mathrm{g}-\mathrm{C}_{3} \mathrm{~N}_{4} \mathrm{QDs}$ via $\mathrm{CB}$ of $\mathrm{TiO}_{2}$ to $\mathrm{Au}$ NPs (similar to that under UV irradiation for $\mathrm{Au} / \mathrm{TiO}_{2}$ photocatalyst) since it is well-known that noble metals work as co-catalyst for hydrogen evolution (negligible activity of bare titania).

Titania nanofibers modified with Au NPs, synthesized by one-step electrospinning of $\mathrm{TiO}_{2}$ and Au precursors, and polyvinylpyrrolidone (PVP) in DMF solution followed by pyrolysis, have also been used for the performance enhancement of dye-sensitized solar cells (DSSCs) [111]. It has been found that $0.5 \mathrm{wt} \%$ is the optimal content of $\mathrm{Au}$ (varied by the concentration of $\mathrm{HAuCl}_{4} \cdot 3 \mathrm{H}_{2} \mathrm{O}$ in the electrospinning solution).

Besides the solid 1D plasmonic photocatalysts (nanowires, nanorods, nanofibers, and so on), hollow 1D photocatalysts (nanotubular arrays or various length of nanotubes) have attracted extensive interests as a support for plasmonic NPs. For example, the photocatalytic activity of Au-modified titania nanotubes (TNTs) have been studied for $\mathrm{CO}_{2}$ conversion to $\mathrm{CH}_{4}$ [112]. It has been found that the activity of TNTs has been significantly improved by Au decoration. Although authors suggest 
plasmonic photocatalysis with an electron transfer from $\mathrm{Au}$ to $\mathrm{TiO}_{2}$, the activity has been tested under $\mathrm{UV} / \mathrm{vis}$, and thus titania excitation could not be excluded (as also observed by vis activity of bare TNTs), and thus Au NPs might work predominantly as an electron acceptor rather than plasmonic sensitizer.

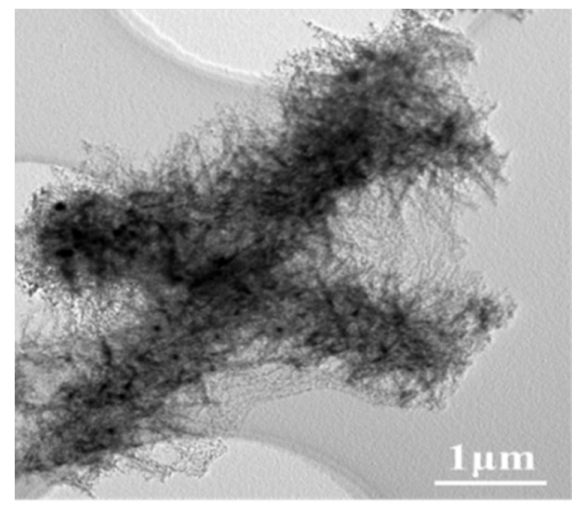

(a)

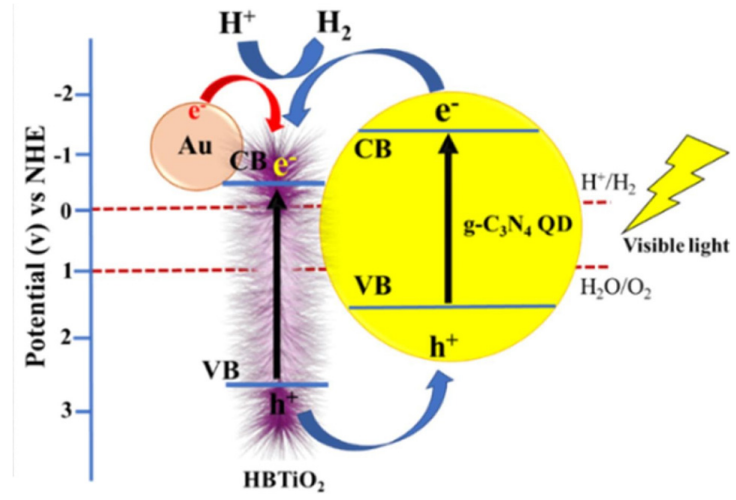

(b)

Figure 15. (a) $\mathrm{TEM}$ of $\mathrm{Au} / \mathrm{TiO} / \mathrm{g}-\mathrm{C}_{3} \mathrm{~N}_{4}$ sample after photocatalytic reaction, (b) the schematic diagram for an electron transfer mechanism under vis excitation; adapted with permission from [110]. Copyrights 2020 Elsevier.

Interesting study has been presented by Fu et al. for single-wall $\mathrm{TiO}_{2}$ nanotube array (TNTA) with in situ deposition of Au NPs [113]. The "hot" electron transfer under vis irradiation has been confirmed by photoelectrochemical study, as shown in Figure 16. The Au/TNTA has been successfully used for DSSCs, and the best performance has reached high power conversion efficiency of $8.93 \%$, which is $190.4 \%$ that of the pristine TNTA-based DSSC.

Besides gold, other noble metals have also been applied for modifications of 1D nanostructures. For example, Ag-TNTA films with the preferential orientation of crystals have been prepared on ITO glass by magnetron sputtering and anodization [114]. It has been found that Ag/TNTA exhibits superior separation/transfer of photo-induced charges, resulting in high photocatalytic activities, i.e., $99.1 \%$ removal of $\mathrm{Cr}(\mathrm{VI})$ during $90 \mathrm{~min}$ of vis illumination. However, in the case of less noble metals, their oxidation should be also considered, and thus the coupled photocatalysts, e.g., $\mathrm{TiO}_{2} / \mathrm{Ag}_{2} \mathrm{O} / \mathrm{Ag}$ are usually obtained $[83,84,86]$. Accordingly, the mechanism of vis response might be quite complex, containing both plasmonic photocatalysis and heterojunction between two semiconductors.

Interesting approach for the preparation of $\mathrm{Ag} / \mathrm{TNT}$ has been proposed by Mazierski et al. via one-step synthesis by anodization of a Ti-Ag alloy [115]. It has been shown that both zero-valent and oxidized forms of silver ( $\mathrm{Ag}$ and $\mathrm{Ag}_{2} \mathrm{O}$ ) have been obtained. Silver NPs have been formed during the in situ generation of Ag ions and are (i) embedded in the TNT walls, (ii) stuck on the external TNT walls, and (iii) placed inside the TNTs. It has been proposed that the enhanced photocatalytic activity under UV irradiation originates from the optimal content of $\mathrm{Ag}_{2} \mathrm{O} / \mathrm{Ag} \mathrm{NPs}$, responsible for decreasing of the number of recombination centers. In contrast, under vis irradiation the activity increases with an increase in the content of both $\mathrm{Ag}_{2} \mathrm{O}$ and $\mathrm{Ag}^{0}$, probably because of more efficient light harvesting by both forms of silver. The electron transfer from $\mathrm{Ag}_{2} \mathrm{O}$ and $\mathrm{Ag}$ (plasmonic excitation) to $\mathrm{CB}$ of titania has been proposed as the first step of photocatalytic reaction. However, zero-valent silver could also work as an electron sink, as already proposed/discussed.

The comparison between 0D and 1D plasmonic photocatalysts have been performed by Wei et al. for OAP (faceted anatase titania) and titanate nanowires (TNWs; precursor used for OAP synthesis) modified with NPs of Au, Ag, and Pt [116]. It has been confirmed that the modifications with noble metals have improved the photocatalytic performance of both semiconductors significantly under UV and vis irradiation. However, the photocatalytic activities of bare and modified OAP samples are much higher than those by TNW samples, probably because of anatase presence, higher crystallinity, and fast electron mobility in faceted NPs. Interestingly, noble metals show different influence on the activity 
depending on the semiconductor support, i.e., gold-modified TNW and platinum-modified OAP exhibit the highest activity for acetic acid decomposition under UV irradiation, whereas silver- and gold-modified samples are the most active under vis irradiation, respectively.

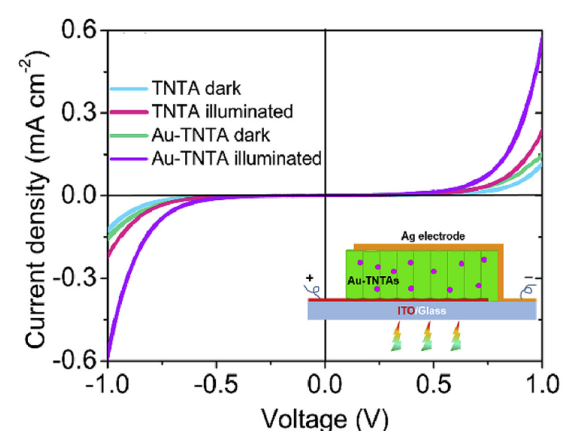

(a)

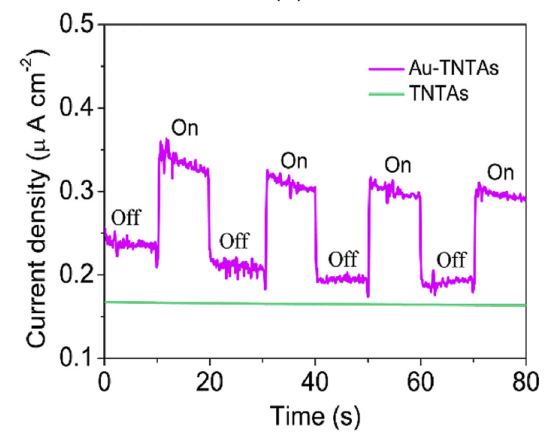

(c)

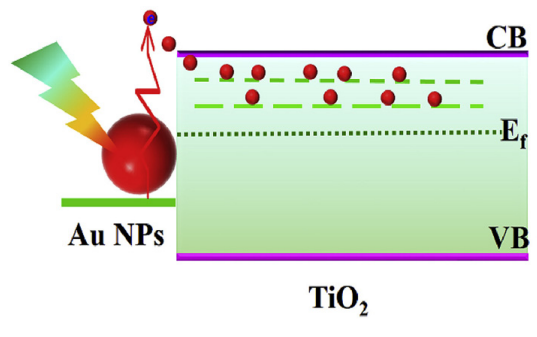

(b)

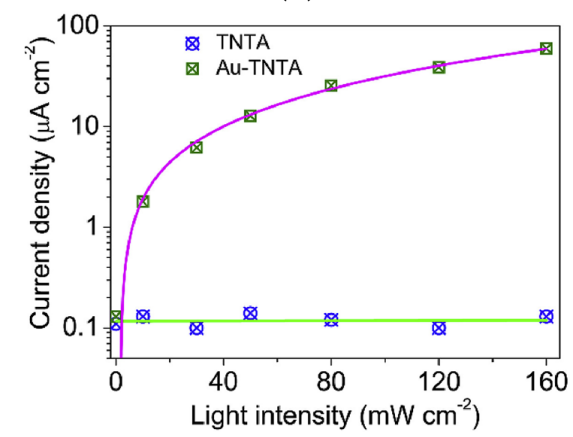

(d)

Figure 16. Hot electron injection induced current response measurement: (a) J-V curves of conductivity test of TNTA (titania nanotube array) and Au-TNTA films in the dark and under illumination $\left(100 \mathrm{~mW} \mathrm{~cm}^{-2}\right)$. The inset shows the structure of the tested electrode; (b) schematic illustration of hot electron injection process from Au-NPs into TNTA; (c) photocurrent response of TNTA and Au-TNTA film toward on/off of the input laser light $\left(520 \mathrm{~nm}, 20 \mathrm{~mW} \mathrm{~cm}^{-2}\right)$; (d) photocurrent variation of TNTA and $\mathrm{Au}$-TNTA film under $520 \mathrm{~nm}$ laser illumination with different light intensity. The applied bias is $1.0 \mathrm{~V}$; adapted with permission from [113]. Copyrights 2019 Elsevier.

\subsection{Two- and Three-Dimensional Plasmonic Photocatalysts}

To improve photocatalytic performance of plasmonic photocatalysts, various advanced nanostructures have been proposed. For example, "advanced superstructure system" composed of titania mesocrystals and NPs of noble metals has been designed to avoid charge carriers' recombination [117]. It has been found that localization of noble metals is crucial for the overall activity, i.e., Au NPs on the basal surface results in much higher activity than that when Au NPs are placed on the lateral one since "hot" electrons easily migrate via titania mesocrystals (similar charge migration as that in faceted titania-DAP), as shown in Figure 17. Because of this anisotropic electron flow, which hinders electron/hole recombination in Au NPs, electrons migrate to the edges of mesocrystals where they might be stored for further reactions. Additionally, in the case of hydrogen evolution reaction, it is known that for plasmonic photocatalysis second metal should be deposited as hydrogen evolution takes place on the metal surface (negligible activity of bare titania and mono-metallic plasmonic photocatalysts because of an electron-deficient noble metal). Accordingly, the deposition of Au NPs on the basal surface and Pt NPs on the lateral surface has caused the high photocatalytic activity under vis irradiation, even for hydrogen evolution (Usually plasmonic photocatalysts are almost inactive for hydrogen evolution due to the opposite direction of electron transfer, i.e., from noble metal to titania, than that under UV irradiation). 


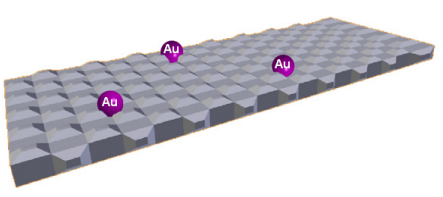

(a)

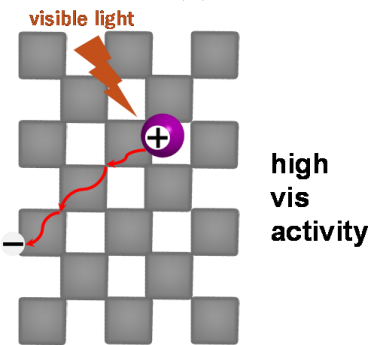

(d)

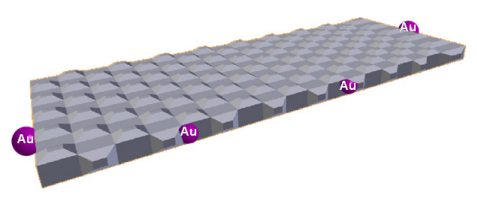

(b)

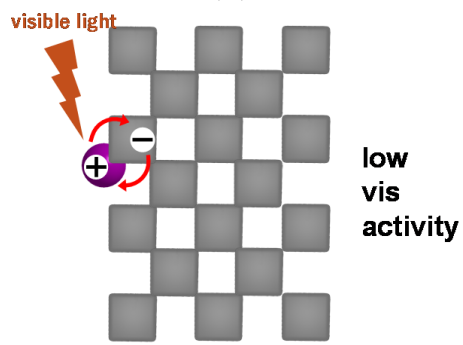

(e)

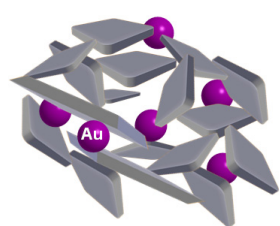

(c)

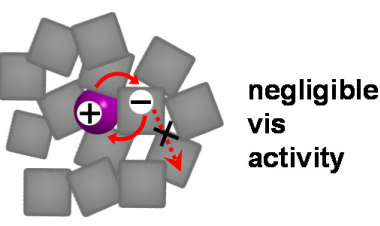

$(\mathbf{f})$

Figure 17. The schematic drawings of: $(\mathbf{a}, \mathbf{b}, \mathbf{d}, \mathbf{e})$ the superstructure composed of titania mesocrystals and $\mathrm{Au}$ NPs deposited on basal $(\mathbf{a}, \mathbf{d})$ and lateral $(\mathbf{b}, \mathbf{e})$ surfaces, and $(\mathbf{c}, \mathbf{f})$ titania mesocrystals with Au NPs; (a-c) side view, (e,f) top view.

The faceted titania nanosheets (2D) have also been used as plasmonic photocatalysts [118]. It has been found that the photocatalytic efficiency of $\mathrm{Au} / \mathrm{TiO}_{2}$ ( $\mathrm{Au}$ NPs selectively deposited on $\{001\}$ facets) for vis-induced $\mathrm{H}_{2}$ evolution depends on the content of $\{001\}$ facets, i.e., activity increase with an increase in the content of $\{001\}$. Besides titania, other 2D materials have been examined, e.g., tin(IV) oxide nanoflakes (2D) modified with Ag NPs [119]. It has been proposed that the activity under vis irradiation is caused by electron transfer from Ag NPs, resulting from plasmonic excitation. However, bare titania is also active, as experiments have been performed for dye discoloration, and thus photocatalyst sensitization by dye should be considered in the overall mechanism.

Moreover, 3D materials have been proposed for plasmonic photocatalysis. Li et al. have decorated $\mathrm{TiO}_{2}$ nanorods with Au NPs via one-step approach to provide a dense coverage of titania nanorods' surfaces with $\mathrm{Au}$ NPs, resulting in high quality of $\mathrm{Au}-\mathrm{TiO}_{2}$ interface, as shown in Figure 18 [120]. This structure provides high activity in vis-induced photoelectrochemical water splitting reaction. FDTD simulations have indicated that the enhanced photoactivity resulting from Au presence is mainly caused by the electric-field amplification effect and hot-electron generation upon LSPR excitation in the visible light.

Interesting comparison between 2D and 3D plasmonic photocatalysts have been provided by Song et al. for rods $(\mathrm{Au} / \mathrm{RR})$ and 3D hierarchical structure $(\mathrm{Au} / 3 \mathrm{DR})$, respectively, as shown in Figure 19 [121]. In the case of visible light $(\lambda>455 \mathrm{~nm})$ induced photocatalytic degradation of p-nitrosodimethylaniline, the reaction efficiency is higher for Au/3DR than that for Au/RR sample. After white-light irradiation on a single particle, a substantial red shift in the LSPR peak and amplified plasmonic coupling in Au/3DR is observed (Figure 19a). To verify the advantage of 3D structure, plasmonic coupling of two Au NPs depending on the irradiated light angle has been calculated by FDTD simulation (Figure 19c). When the tilted angle is lower than $45^{\circ}$, the transverse mode becomes more dominant than the longitudinal mode and a blue shift with decreased intensity of electromagnetic (EM) field in the LSPR peak occurs. When the tilted angle is higher than $45^{\circ}$, the longitudinal mode is formed and the red shift in the LSPR peak occurs, reaching the maximum at $90^{\circ}$. Rods from $A u / R R$ are randomly oriented in the photocatalytic system and plasmonic coupling effects in all angles are negatively averaged (Figure 19d). On the other hand, rods in the Au/3DR are oriented in an orderly manner and most of Au NP array can be irradiated by light in the vertical direction (longitudinal plasmonic coupling), which leads to the LSPR peak of Au/3DR to become red-shift with high intensity. 


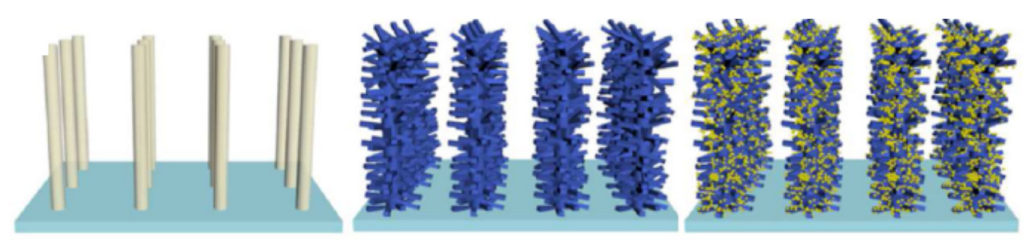

(a)

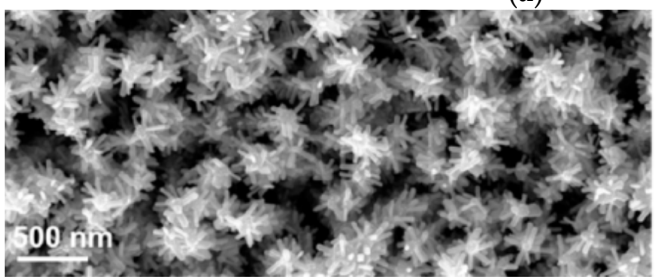

(b)

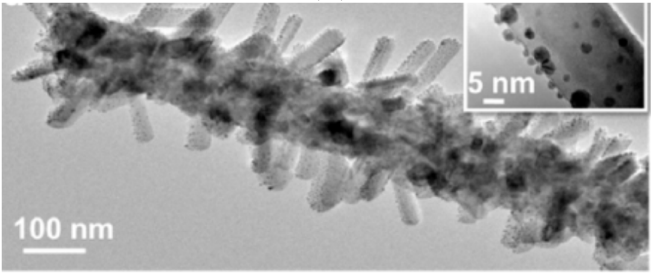

(d)

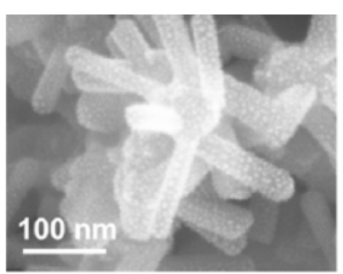

(c)

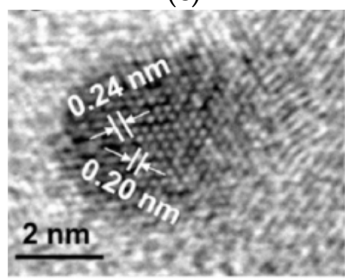

(e)

Figure 18. (a) Schematic representation of the fabrication of Au-NP-decorated $3 \mathrm{D}$ branched $\mathrm{TiO}_{2} \mathrm{NR}$ architectures; (b) top-viewed SEM image of Au NP-3D TiO 2 NR arrays; (c) SEM image showing homogeneously distributed $\mathrm{Au}$ NPs on the entire $\mathrm{TiO}_{2}$ surface; (d) TEM image of an individual branched $\mathrm{TiO}_{2}$ NR array. Inset: Single $\mathrm{TiO}_{2}$ NR decorated with Au NPs; (e) HRTEM image of a Au NP residing on the $\mathrm{TiO}_{2}$ surface; adapted with permission from [120]. Copyright 2017 ACS.

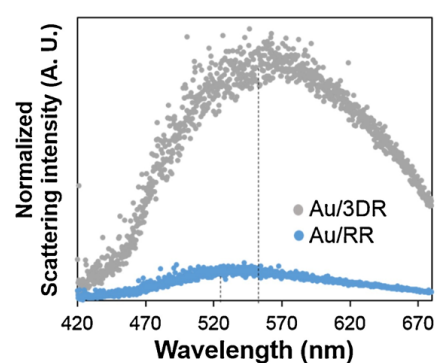

(a)

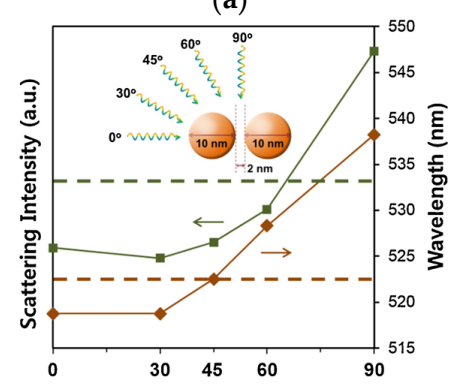

(c)

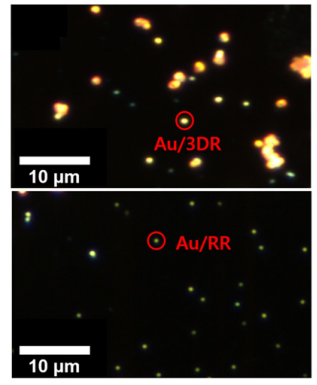

(b)
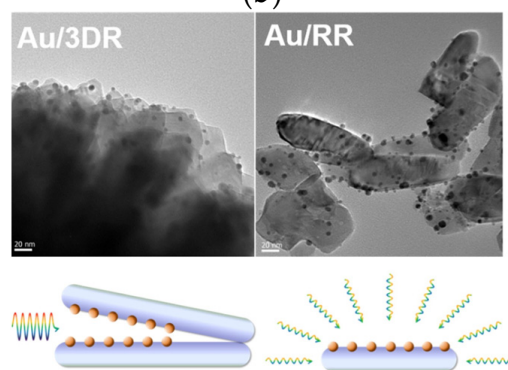

(d)

Figure 19. (a,b) Dark field images of $\mathrm{Au} / 3 \mathrm{DR}$ and $\mathrm{Au} / \mathrm{RR}$ (typical particles—red circles); (c) FDTD simulations performed according to inset scheme of coupled Au NPs with light irradiation in different directions; the values of original $10 \mathrm{~nm}$ Au NP indicated by dotted lines; (d) TEM images (top) of $\mathrm{Au} / 3 \mathrm{DR}$ and $\mathrm{Au} / \mathrm{RR}$ with simplified schemes including light irradiation (bottom); adapted with permission from [121]. Copyright 2016 Elsevier. 
For activity improvements of any photocatalytic materials, two main strategies are mainly considered, i.e., inhibition of charge carriers' recombination and efficient light harvesting. Accordingly, various strategies for charge carriers' separation have been proposed, as already discussed in this review. In the case of efficient light harvesting, the preparation of highly polydisperse NPs of noble metals (broad LSPR [38,56]) and co-modifications with other metals [98], metal oxides [96,122] and metal complexes [105-107] have been investigated. Recently, another strategy has been proposed, i.e., using semiconductors in the form of photonic crystals with photonic bandgap and slow photon effect. Usually titania inverse opal, prepared from respective opal (e.g., silica or polystyrene (PS) sacrificial template), is used as photonic crystal for support of noble metals, as shown in Figure 20. It has been proposed that the overlapping of photonic bandgap with LSPR of noble metal causes the significant enhancement of the photocatalytic activity (photons are efficiently used by multi-scattering effect), as already comprehensively presented in the review paper on the photonic crystals for plasmonic photocatalysis [123]. Although, efficient light harvesting and high photocatalytic activity have been achieved in some cases [124-126], there are various challenges facing the photonic crystal-based plasmonic photocatalysts, including complex synthesis, delicate nature (easy destruction of opal/inverse opal structure), and still unknown key factors of the high photocatalytic performance. Besides that, it seems that probably this is the hottest topic of plasmonic photocatalysis in recent years, and more studies/reports are expected in the nearest future, based on the excellent light harvesting ability, resulting from extraordinary optical properties in such nanostructures (similar to metal films and sub-wavelength hole arrays $[127,128])$.

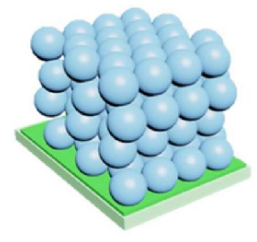

PS opal

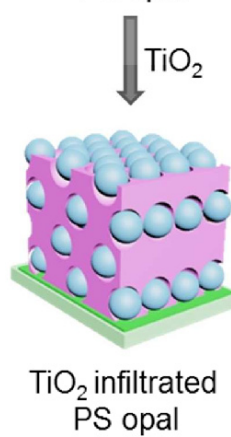

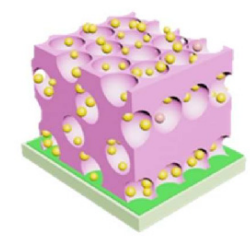

$\mathrm{TiO}_{2} @ \mathrm{Au}$

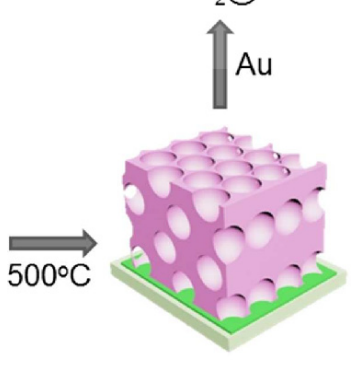

$\mathrm{TiO}_{2}$

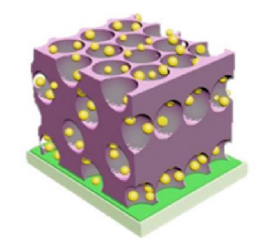

$\mathrm{TiO}_{2} @ \mathrm{rGO} @ \mathrm{Au}$

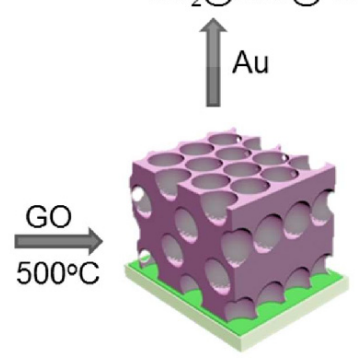

$\mathrm{TiO}_{2} @ \mathrm{rGO}$

Figure 20. The schematic drawings of preparation of noble-metal-modified photonic crystals $\left(\mathrm{TiO}_{2}\right.$ inverse opal and rGO-modified $\mathrm{TiO} 2$ inverse opal), adapted from [129]. Copyright 2017 ACS.

\subsection{Other Plasmonic Photocatalysts}

Another recent research on new plasmonic photocatalysts focuses on ferroelectrics, which have been applied in photocatalysis reactions, since the polarization of ferroelectrics might improve the charge carriers' separation, and thus the photocatalytic activities [130]. Accordingly, a range of ferroelectrics has attracted interests in photocatalysis, whereas their photocatalytic performance still needs to be improved. Ferroelectrics usually have a large bandgap, a low absorption coefficient, and a low photon conversion efficiency when used alone. Therefore, various methods have been tried to enhance their photocatalytic efficiency, among which the modification with NPs of noble metals turns out to be efficient. For example, Su et al. have enhanced the activity of ferroelectric $\mathrm{BaTiO}_{3}$ after its modification with Ag [131]. Besides the ferroelectricity and specific charge-transfer kinetics in the $\mathrm{Ag} / \mathrm{BaTiO}_{3}$ hybrid, LSPR of $\mathrm{Ag}$ has been suggested to contribute to the enhancement as well. Wu et al. 
have prepared a ternary Z-scheme heterojunction photocatalyst of $\mathrm{BaTiO}_{3} / \mathrm{Au} / \mathrm{g}-\mathrm{C}_{3} \mathrm{~N}_{4}$, in which $\mathrm{Au} \mathrm{NPs}$ besides acting as an electron mediator, could absorb visible light by LSPR effect to inject "hot" electrons into $\mathrm{CB}$ of $\mathrm{g}-\mathrm{C}_{3} \mathrm{~N}_{4}$ to participate in the photocatalytic reactions [132]. Recently, a dual-modified photocatalyst of $\mathrm{BaTiO}_{3}$ has been synthesized, i.e., $\mathrm{Ag} / \mathrm{BaTiO}_{3} / \mathrm{MnO}_{\mathrm{x}}$, where LSPR of Ag NPs on $\mathrm{BaTiO}_{3}$ is noticed, but its influence on the photocatalytic reactions has not been discussed [133]. Lan et al. have observed an enhanced photocatalytic activity in one-dimensional $\mathrm{KNbO}_{3}$ nanowires (1D) modified with Au NPs due to LSPR and interband transitions on Au NPs, depending on the size of Au NPs, i.e., an increase in the activity with an increase in the size of Au NPs from 5 to $10 \mathrm{~nm}$ [134] (which might suggest more important LSPR effect for the overall activity). In another study, it has been proposed that the improved photocatalytic activity and stability of $\mathrm{Ag} / \mathrm{AgNbO}_{3}$ is caused by LSPR effect, ferroelectric polarization, specific exposed facets, and high crystallinity at the heterogeneous interface [73]. Meanwhile, $\mathrm{BiFeO}_{3}$ (one of the most promising multiferroic materials) decorated with NPs of Au and Ag has proven to be active under vis irradiation due to strong field enhancement especially near Ag NPs [135]. Similarly, as mentioned in former paragraphs, the presence of LSPR does not guarantee its participation in promoting the photocatalytic activities. For example, Cui et al. have coated $\mathrm{BaTiO}_{3}$ with nanostructured $\mathrm{Ag}$, resulting in vis absorption due to LSPR, but photo-decolorization of RhB (under both UV- and visible-light-blocking filters) indicates that "hot" electrons do not contribute to the photocatalytic activity [136]. Besides, it has been proposed that the geometry of metal deposits on ferroelectric substrate plays an important role in enlarging or inhibiting the polarization effect, and thus the metal deposits should not be too thick to block the effect from polarization [137]. Chao et al. have indicated that in the case of $\mathrm{Au} / \mathrm{BaTiO}_{3}$ the "hot" electrons (LSPR of $\mathrm{Au}$ ) have only little effect on the improvement of vis photocatalytic performance [138].

Summarizing, as pointed by Kumar et al. it is important to realize that the integration of plasmonic metals with ferroelectrics might be beneficial for two aspects: (1) The injected charge carriers are effectively driven to spatially separate over the ferroelectric particles; and (2) tuning the Schottky barrier height, e.g., by changing the chemical composition of noble-metal/semiconductor, thus providing an interfacial contact that favors the hot charge injection [139]. Both effects can prolong the lifetimes of both the excited electrons and holes. Therefore, for effective utilization of LSPR in ferroelectric-based photocatalysts, more efforts are needed to reveal the critical parameters and achieve higher photocatalytic efficiency.

\section{Summary}

Plasmonic photocatalysts have been intensively investigated in recent years, because of tunable vis activity and broad possibilities of applications, including environmental purification (decomposition of organic compounds and inactivation of microorganisms) and solar energy conversion (water splitting, photocurrent generation, $\mathrm{CO}_{2}$ conversion-artificial photosynthesis). Although, plasmonic photocatalysts have shown vis response and high potential for various applications, the activity under vis irradiation is usually too low for commercialization. Accordingly, morphology design has been intensively studied to improve the photocatalytic performance. Faceted nanoparticles, aerogels, core/shells, Janus particles, photonic crystals, 1D, 2D, and 3D nanostructures have been proposed as excellent support for noble metals. However, it should be pointed out that some morphology might result in a decrease of photocatalytic activity, e.g., highly UV-active decahedral anatase with noble-metal NPs deposited on $\{101\}$ facets accelerates charge carriers' recombination under vis irradiation.

The comparison between various nanostructures is quite difficult as different irradiation sources, photoreactors, tested compounds, and reaction conditions have been used, and only several studies show apparent quantum yields. Moreover, solar radiation or solar simulators are commonly used for activity testing, and thus different mechanism is expected, i.e., excitation of semiconductor rather than plasmon resonance. Accordingly, even if "plasmonic photocatalysis" term is used in the title of some reports, it does not guarantee that really plasmonic photocatalysis has been investigated. 
It should be reminded that noble metals have been known as an electron sink for ca. 50 years, and thus improving photocatalytic activity of wide-bandgap semiconductors under their excitation. Moreover, for some reactions noble metals are necessary as co-catalyst, e.g., hydrogen evolution, as bare semiconductors are hardly active. Additionally, activity tests should not be performed for dye discoloration, as photocatalyst sensitization by dye might be the predominant mechanism of their degradation rather than plasmonic photocatalysis.

Another important issue is the mechanism clarifications, as three main mechanisms have been postulated, i.e., energy transfer, electron transfer and plasmonic heating. Although, plasmonic heating has not been considered as the main mechanism in majority of studies because of the inefficiency to cleave the chemical bonds, it might not be excluded for antimicrobial activity as microorganisms are highly sensitive to any environmental changes. Although, it is hard to find a direct proof for any mechanism, and only indirect proofs have been shown, it might be concluded that the mechanism depends on the morphology.

The role of morphology is undoubtedly an important issue, which should be taken into consideration during design of new plasmonic photocatalysts. Combined with the presented state-of-the-art, future efforts to prepare morphologically controlled plasmonic materials should focus, among others, on the following points:

(i) Better understanding of the destination photocatalytic reaction mechanism and synergistic effects between LSPR phenomenon and particle morphology is necessary-the usage of advanced characterization techniques to perform a detailed analysis of physicochemical properties of prepared materials coupled with providing theoretical simulations and calculations to deeply understand these synergistic interactions.

(ii) The issue of the reaction selectivity by adjusting morphological properties of plasmonic photocatalysts (e.g., understanding the role of titania crystal facets configuration for the course of photocatalytic $\mathrm{CO}_{2}$ reduction) should be considered in more detail.

Although, many aspects of plasmonic photocatalysts are still unknown, unclear, or even inconsistent, it is thought that plasmonic photocatalysts might be successfully commercialized in the nearest future.

Funding: This research was financially supported by National Natural Science Foundation of China (NSFC; contract No. 51802087) and "Yugo-Sohatsu Kenkyu" for an Integrated Research Consortium on Chemical Sciences (IRCCS) project from Ministry of Education and Culture, Sport, Science and Technology-Japan (MEXT).

Conflicts of Interest: The authors declare no conflict of interest.

\section{References}

1. Balcerski, W.; Ryu, S.Y.; Hoffmann, M.R. Visible-Light Photoactivity of Nitrogen-Doped $\mathrm{TiO}_{2}$ : Photo-oxidation of $\mathrm{HCO}_{2} \mathrm{H}$ to $\mathrm{CO}_{2}$ and $\mathrm{H}_{2} \mathrm{O}$. J. Phys. Chem. C 2007, 111, 15357-15362. [CrossRef]

2. Hoffmann, M.R.; Martin, S.T.; Choi, W.Y.; Bahnemann, D.W. Environmental applications of semiconductor photocatalysis. Chem. Rev. 1995, 95, 69-96. [CrossRef]

3. Fujishima, A.; Honda, K. Electrochemical photolysis of water at a semiconductor electrode. Nature 1972, 238, 37-38. [CrossRef] [PubMed]

4. Abe, R.; Shinmei, K.; Koumura, N.; Hara, K.; Ohtani, B. Visible-light-induced water splitting based on Two-step photoexcitation between dye-sensitized layered niobate and tungsten oxide photocatalysts in the presence of a triiodide/iodide shuttle redox mediator. J. Am. Chem. Soc. 2013, 135, 16872-16884. [CrossRef] [PubMed]

5. Herrmann, J.M. Heterogeneous photocatalysis: State of the art and present applications. Top. Catal. 2005, 34, 49-65. [CrossRef]

6. Wang, K.L.; Janczarek, M.; Wei, Z.S.; Raja-Mogan, T.; Endo-Kimura, M.; Khedr, T.M.; Ohtani, B.; Kowalska, E. Morphology- and crystalline composition-governed activity of titania-based photocatalysts: Overview and perspective. Catalysts 2019, 9, 1054. [CrossRef] 
7. Murakami, N.; Katayama, S.; Nakamura, M.; Tsubota, T.; Ohno, T. Dependence of photocatalytic activity on aspect ratio of shape-controlled rutile titanium(IV) oxide nanorods. J. Phys. Chem. C 2011, 115, 419-424. [CrossRef]

8. Amano, F.; Yasumoto, T.; Mahaney, O.O.P.; Uchida, S.; Shibayama, T.; Terada, Y.; Ohtani, B. Highly active titania photocatalyst particles of controlled crystal phase, size, and polyhedral shapes. Top. Catal. 2010, 53, 455-461. [CrossRef]

9. Amano, F.; Prieto-Mahaney, O.O.; Terada, Y.; Yasumoto, T.; Shibayama, T.; Ohtani, B. Decahedral single-crystalline particles of anatase titanium(IV) oxide with high photocatalytic activity. Chem. Mater. 2009, 21, 2601-2603. [CrossRef]

10. Janczarek, M.; Kowalska, E.; Ohtani, B. Decahedral-shaped anatase titania photocatalyst particles: Synthesis in a newly developed coaxial-flow gas-phase reactor. Chem. Eng. J. 2016, 289, 502-512. [CrossRef]

11. Wei, Z.S.; Kowalska, E.; Ohtani, B. Enhanced photocatalytic activity by particle morphology: Preparation, characterization, and photocatalytic activities of octahedral anatase titania particles. Chem. Lett. 2014, 43, 346-348. [CrossRef]

12. Wei, Z.; Kowalska, E.; Verrett, J.; Colbeau-Justin, C.; Remita, H.; Ohtani, B. Morphology-dependent photocatalytic activity of octahedral anatase particles prepared by ultrasonication-hydrothermal reaction of titanates. Nanoscale 2015, 7, 12392-12404. [CrossRef] [PubMed]

13. Zaleska, A. Doped-TiO 2 : A review. Recent Pat. Eng. 2008, 2, 157-164. [CrossRef]

14. Asahi, R.; Morikawa, T.; Ohwaki, T.; Aoki, K.; Taga, Y. Visible-light photocatalysis in nitrogen-doped titanium oxides. Science 2001, 293, 269-271. [CrossRef]

15. Ohno, T.; Akiyoshi, M.; Umebayashi, T.; Asai, K.; Mitsui, T.; Matsumura, M. Preparation of S-doped $\mathrm{TiO}_{2}$ photocatalysts and their photocatalytic activities under visible light. Appl. Catal. A Gen. 2004, 265, 115-121. [CrossRef]

16. Beranek, R.; Kisch, H. Surface-modified anodic $\mathrm{TiO}_{2}$ films for visible light photocurrent response. Electrochem. Commun. 2007, 9, 761-766. [CrossRef]

17. Janus, M.; Tryba, B.; Inagaki, M.; Morawski, A.W. New preparation of a carbon- $\mathrm{TiO}_{2}$ photocatalyst by carbonization of n-hexane deposited on $\mathrm{TiO}_{2}$. Appl. Catal. B Environ. 2004, 52, 61-67. [CrossRef]

18. Sclafani, A.; Mozzanega, M.N.; Pichat, P. Effect of silver deposits on the photocatalytic activity of titanium dioxide samples for the dehydrogenation or oxidation of 2-propanol. J. Photochem. Photobiol. A Chem. 1991, 59, 181-189. [CrossRef]

19. Wang, K.L.; Endo-Kimura, M.; Belchi, R.; Zhang, D.; Habert, A.; Boucle, J.; Ohtani, B.; Kowalska, E.; Herlin-Boime, N. Carbon/graphene-modified titania with enhanced photocatalytic activity under UV and vis irradiation. Materials 2019, 12, 4158. [CrossRef]

20. Di Paola, A.; Palmisano, L.; Venezia, A.M.; Augugliaro, V. Coupled semiconductor systems for photocatalysis. Preparation and characterization of polycrystalline mixed $\mathrm{WO}_{3} / \mathrm{WS}_{2}$ powders. J. Phys. Chem. B 1999, 103, 8236-8244. [CrossRef]

21. Endo-Kimura, M.; Janczarek, M.; Bielan, Z.; Zhang, D.; Wang, K.; Markowska-Szczupak, A.; Kowalska, E. Photocatalytic and antimicrobial properties of $\mathrm{Ag}_{2} \mathrm{O} / \mathrm{TiO}_{2}$ heterojunction. ChemEngineering 2019, $3,3$. [CrossRef]

22. Janczarek, M.; Wang, K.L.; Kowalska, E. Synergistic effect of $\mathrm{Cu}_{2} \mathrm{O}$ and urea as modifiers of $\mathrm{TiO}_{2}$ for enhanced visible light activity. Catalysts 2018, 8, 240. [CrossRef]

23. Kraeutler, B.; Bard, A.J. Heterogeneous photocatalytic preparation of supported catalysts. Photodeposition of platinum on $\mathrm{TiO}_{2}$ powder and other substrates. J. Am. Chem. Soc. 1978, 100, 4317-4318. [CrossRef]

24. Xu, A.-W.; Gao, Y.; Liu, H.-Q. The preparation, characterization, and their photocatalytic activities of rare-earth-doped $\mathrm{TiO}_{2}$ nanoparticles. J. Catal. 2002, 207, 151-157. [CrossRef]

25. Morikawa, T.; Asahi, R.; Ohwaki, T.; Aoki, K.; Taga, Y. Band-gap narrowing of titanium dioxide by nitrogen doping. Jpn. J. Appl. Phys. 2001, 40, L561-L563. [CrossRef]

26. Anpo, M. Use of visible light. Second-generation titanium oxide photocatalysts prepared by the application of an advanced metal ion-implantation method. Pure Appl. Chem. 2000, 72, 1787-1792. [CrossRef]

27. Wang, Y.Q.; Cheng, H.M.; Zhang, L.; Hao, Y.Z.; Ma, J.M.; Xu, B.; Li, W.H. The preparation, characterization, photoelectrochemical and photocatalytic properties of lanthanide metal-ion-doped $\mathrm{TiO}_{2}$ nanoparticles. J. Mol. Catal. A Chem. 2000, 151, 205-216. [CrossRef] 
28. Hirano, K.; Suzuki, E.; Ishikawa, A.; Moroi, T.; Shiroishi, H.; Kaneko, M. Sensitization of TiO 2 particles by dyes to achieve $\mathrm{H}_{2}$ evolution by visible light. J. Photochem. Photobiol. A 2000, 136, 157-161. [CrossRef]

29. Tian, Y.; Liu, H.; Zhao, G.; Tatsuma, T. Shape-controlled electrodeposition of gold nanostructures. J. Phys. Chem. B 2006, 110, 23478-23481. [CrossRef]

30. Tian, Y.; Tatsuma, T. Mechanisms and applications of plasmon-induced charge separation at $\mathrm{TiO}_{2}$ films loaded with gold nanoparticles. J. Am. Chem. Soc. 2005, 127, 7632-7637. [CrossRef]

31. Liu, Z.; Hou, W.; Pavaskar, P.; Aykol, M.; Cronin, S.B. Plasmon resonance enhancement of photocatalytic water splitting under visible illumination. Nano Lett. 2011, 11, 1111-1116. [CrossRef] [PubMed]

32. Hou, W.B.; Hung, W.H.; Pavaskar, P.; Goeppert, A.; Aykol, M.; Cronin, S.B. Photocatalytic conversion of $\mathrm{CO}_{2}$ to hydrocarbon fuels via plasmon-enhanced absorption and metallic interband transitions. ACS Catal. 2011, 1, 929-936. [CrossRef]

33. Ueno, K.; Misawa, H. Surface plasmon-enhanced photochemical reactions. J. Photochem. Photobiol. C 2013, 15, 31-52. [CrossRef]

34. Nishijima, Y.; Ueno, K.; Yokata, Y.; Murakoshi, K.; Misawa, H. Plasmon-assisted photocurrent generation from visible to near-infrared wavelength using a Au-nanorods $/ \mathrm{TiO}_{2}$ electrode. J. Phys. Chem. Lett. 2010, 1, 2031-2036. [CrossRef]

35. Bouhadoun, S.; Guillard, C.; Dapozze, F.; Singh, S.; Amans, D.; Boucle, J.; Herlin-Boime, N. One step synthesis of $\mathrm{N}$-doped and $\mathrm{Au}$-loaded $\mathrm{TiO}_{2}$ nanoparticles by laser pyrolysis: Application in photocatalysis. Appl. Catal. B Environ. 2015, 174, 367-375. [CrossRef]

36. Hou, W.; Liu, Z.; Pavaskar, P.; Hsuan Hung, W.; Cronin, S.B. Plasmonic enhancement of photocatalytic decomposition of methyl orange under visible light. J. Catal. 2011, 277, 149-153. [CrossRef]

37. Seh, Z.W.; Liu, S.W.; Low, M.; Zhang, S.-Y.; Liu, Z.; Mlayah, A.; Han, M.-Y. Janus Au-TiO 2 photocatalysts with strong localization of plasmonic near fields for efficient visible-light hydrogen generation. Adv. Mater. 2012, 24, 2310-2314. [CrossRef]

38. Kowalska, E.; Abe, R.; Ohtani, B. Visible light-induced photocatalytic reaction of gold-modified titanium(IV) oxide particles: Action spectrum analysis. Chem. Commun. 2009, 241-243. [CrossRef] [PubMed]

39. Du, L.; Furube, A.; Hara, K.; Katoh, R.; Tachiya, M. Plasmon induced electron transfer at gold-TiO ${ }_{2}$ interface under femtosecond near-IR two photon excitation. Thin Solid Films 2009, 158, 861-864. [CrossRef]

40. Du, L.C.; Furube, A.; Yamamoto, K.; Hara, K.; Katoh, R.; Tachiya, M. Plasmon-induced charge separation and recombination dynamics in gold- $\mathrm{TiO}_{2}$ nanoparticle systems: Dependence on $\mathrm{TiO}_{2}$ particle size. J. Phys. Chem. C 2009, 113, 6454-6462. [CrossRef]

41. Caretti, I.; Keulemans, M.; Verbruggen, S.W.; Lenaerts, S.; Van Doorslaer, S. Light-induced processes in plasmonic gold $/ \mathrm{TiO}_{2}$ photocatalysts studied by electron paramagnetic resonance. Top. Catal. 2015, 58, 776-782. [CrossRef]

42. Priebe, J.B.; Radnik, J.; Lennox, A.J.J.; Pohl, M.M.; Karnahl, M.; Hollmann, D.; Grabow, K.; Bentrup, U.; Junge, H.; Beller, M.; et al. Solar hydrogen production by plasmonic $\mathrm{Au}-\mathrm{TiO}_{2}$ catalysts: Impact of synthesis protocol and $\mathrm{TiO}_{2}$ phase on charge transfer efficiency and $\mathrm{H}_{2}$ evolution rates. ACS Catal. 2015, 5, 2137-2148. [CrossRef]

43. Mendez-Medrano, M.G.; Kowalska, E.; Lehoux, A.; Herissan, A.; Ohtani, B.; Rau, S.; Colbeau-Justin, C.; Rodriguez-Lopez, J.L.; Remita, H. Surface modification of $\mathrm{TiO}_{2}$ with $\mathrm{Au}$ nanoclusters for efficient water treatment and hydrogen generation under visible light. J. Phys. Chem. C 2016, 120, 25010-25022. [CrossRef]

44. Wei, Z.; Janczarek, M.; Endo, M.; Colbeau-Justin, C.; Ohtani, B.; Kowalska, E. Silver-modified octahedral anatase particles as plasmonic photocatalyst. Catal. Today 2018, 310, 19-25. [CrossRef] [PubMed]

45. Sakai, N.; Fujiwara, Y.; Takahashi, Y.; Tatsuma, T. Plasmon-resonance-based generation of cathodic photocurrent at electrodeposited gold nanoparticles coated with $\mathrm{TiO}_{2}$ films. Chem. Phys. Chem. 2009, 10, 766-769. [CrossRef]

46. Chen, X.; Zhu, H.-Y.; Zhao, J.-C.; Zheng, Z.-F.; Gao, X.-P. Visible-light-driven oxidation of organic contaminants in air with gold nanoparticle catalysts on oxide supports. Angew. Chem. Int. Ed. 2008, 47, 5353-5356. [CrossRef]

47. Wang, C.J.; Ranasingha, O.; Natesakhawat, S.; Ohodnicki, P.R.; Andio, M.; Lewis, J.P.; Matranga, C. Visible light plasmonic heating of $\mathrm{Au}-\mathrm{ZnO}$ for the catalytic reduction of $\mathrm{CO}_{2}$. Nanoscale 2013, 5, 6968-6974. [CrossRef] 
48. Mohamed, R.M.; Aazam, E.S. Characterization and catalytic properties of nano-sized Au metal catalyst on titanium containing high mesoporous silica (Ti-HMS) synthesized by photo-sssisted deposition and impregnation methods. Int. J. Photoenergy 2011. [CrossRef]

49. Trammell, S.A.; Nita, R.; Moore, M.; Zabetakis, D.; Chang, E.; Knight, D.A. Accelerating the initial rate of hydrolysis of methyl parathion with laser excitation using monolayer protected $10 \mathrm{~nm}$ Au nanoparticles capped with a $\mathrm{Cu}$ (bpy) catalyst. Chem. Commun. 2012, 48, 4121-4123. [CrossRef] [PubMed]

50. Mukherjee, S.; Libisch, F.; Large, N.; Neumann, O.; Brown, L.V.; Cheng, J.; Lassiter, J.B.; Carter, E.A.; Nordlander, P.; Halas, N.J. Hot electrons do the impossible: Plasmon-induced dissociation of $\mathrm{H}_{2}$ on $\mathrm{Au}$. Nano Lett. 2013, 13, 240-247. [CrossRef] [PubMed]

51. Cushing, S.K.; Li, J.T.; Meng, F.K.; Senty, T.R.; Suri, S.; Zhi, M.J.; Li, M.; Bristow, A.D.; Wu, N.Q. Photocatalytic activity enhanced by plasmonic resonant energy transfer from metal to semiconductor. J. Am. Chem. Soc. 2012, 134, 15033-15041. [CrossRef] [PubMed]

52. Silva, C.G.; Juarez, R.; Marino, T.; Molinari, R.; Garcia, H. Influence of excitation wavelength (UV or visible light) on the photocatalytic activity of titania containing gold nanoparticles for the generation of hydrogen or oxygen from water. J. Am. Chem. Soc. 2011, 133, 595-602. [CrossRef]

53. Son, M.S.; Im, J.E.; Wang, K.K.; Oh, S.L.; Kim, Y.R.; Yoo, K.H. Surface plasmon enhanced photoconductance and single electron effects in mesoporous titania nanofibers loaded with gold nanoparticles. Appl. Phys. Lett. 2010, 96, 023115. [CrossRef]

54. Kominami, H.; Tanaka, A.; Hashimoto, K. Gold nanoparticles supported on cerium(IV) oxide powder for mineralization of organic acids in aqueous suspensions under irradiation of visible light of $\lambda=530 \mathrm{~nm}$. Appl. Catal. A Gen. 2011, 397, 121-126. [CrossRef]

55. Ilie, M.; Cojocaru, B.; Parvulescu, V.I.; Garcia, H. Improving $\mathrm{TiO}_{2}$ activity in photo-production of hydrogen from sugar industry wastewaters. Int. J. Hydrogen Energy 2011, 36, 15509-15518. [CrossRef]

56. Kowalska, E.; Mahaney, O.O.P.; Abe, R.; Ohtani, B. Visible-light-induced photocatalysis through surface plasmon excitation of gold on titania surfaces. Phys. Chem. Chem. Phys. 2010, 12, 2344-2355. [CrossRef] [PubMed]

57. Endo, M.; Wei, Z.S.; Wang, K.L.; Karabiyik, B.; Yoshiiri, K.; Rokicka, P.; Ohtani, B.; Markowska-Szczupak, A.; Kowalska, E. Noble metal-modified titania with visible-light activity for the decomposition of microorganisms. Beilstein J. Nanotech. 2018, 9, 829-841. [CrossRef]

58. Mkhalid, I.A. Visible light photocatalytic synthesis of aniline with an $\mathrm{Au} / \mathrm{LaTiO}_{3}$ nanocomposites. J. Alloy Compd. 2015, 631, 298-302. [CrossRef]

59. Seo, J.H.; Jeon, W.I.; Dembereldorj, U.; Lee, S.Y.; Joo, S.W. Cytotoxicity of serum protein-adsorbed visible-light photocatalytic Ag/AgBr/TiO 2 nanoparticles. J. Hazard. Mater. 2011, 198, 347-355. [CrossRef]

60. Zielińska-Jurek, A.; Kowalska, E.; Sobczak, J.W.; Lisowski, W.; Ohtani, B.; Zaleska, A. Preparation and characterization of monometallic $(\mathrm{Au})$ and bimetallic $(\mathrm{Ag} / \mathrm{Au})$ modified-titania photocatalysts activated by visible light. Appl. Catal. B Environ. 2011, 101, 504-514. [CrossRef]

61. Wang, K.L.; Wei, Z.S.; Ohtani, B.; Kowalska, E. Interparticle electron transfer in methanol dehydrogenation on platinum-loaded titania particles prepared from P25. Catal. Today 2018, 303, 327-333. [CrossRef]

62. Yang, H.G.; Liu, G.; Qiao, S.Z.; Sun, C.H.; Jin, Y.G.; Smith, S.C.; Zou, J.; Cheng, H.M.; Lu, G.Q. Solvothermal synthesis and photoreactivity of anatase $\mathrm{TiO}_{2}$ nanosheets with dominant $\{001\}$ facets. J. Am. Chem. Soc. 2009, 131, 4078-4083. [CrossRef] [PubMed]

63. Tachikawa, T.; Yamashita, S.; Majima, T. Evidence for crystal-face-dependent $\mathrm{TiO}_{2}$ photocatalysis from single-molecule imaging and kinetic analysis. J. Am. Chem. Soc. 2011, 133, 7197-7204. [CrossRef] [PubMed]

64. Fazio, G.; Ferrighi, L.; Di Valentin, C. Spherical versus faceted anatase $\mathrm{TiO}_{2}$ nanoparticles: A model study of structural and electronic properties. J. Phys. Chem. C 2015, 119, 20735-20746. [CrossRef]

65. Wei, Z.; Kowalska, E.; Wang, K.; Colbeau-Justin, C.; Ohtani, B. Enhanced photocatalytic activity of octahedral anatase particles prepared by hydrothermal reaction. Catal. Today 2017, 280, 29-36. [CrossRef]

66. Wei, Z.; Kowalska, E.; Ohtani, B. Influence of post-treatment operations on structural properties and photocatalytic activity of octahedral anatase titania particles prepared by an ultrasonication-hydrothermal reaction. Molecules 2014, 19, 19573-19587. [CrossRef]

67. Zhu, J.A.; Wang, S.H.; Bian, Z.F.; Xie, S.H.; Cai, C.L.; Wang, J.G.; Yang, H.G.; Li, H.X. Solvothermally controllable synthesis of anatase $\mathrm{TiO}_{2}$ nanocrystals with dominant $\{001\}$ facets and enhanced photocatalytic activity. CrystEngComm 2010, 12, 2219-2224. [CrossRef] 
68. Yang, H.G.; Sun, C.H.; Qiao, S.Z.; Zou, J.; Liu, G.; Smith, S.C.; Cheng, H.M.; Lu, G.Q. Anatase TiO 2 single crystals with a large percentage of reactive facets. Nature 2008, 453, 638-641. [CrossRef]

69. Murakami, N.; Kurihara, Y.; Tsubota, T.; Ohno, T. Shape-controlled anatase titanium(IV) oxide particles prepared by hydrothermal treatment of peroxo titanic acid in the presence of polyvinyl alcohol. J. Phys. Chem. C 2009, 113, 3062-3069. [CrossRef]

70. Ballestas-Barrientos, A.; Li, X.B.; Yick, S.; Yuen, A.; Masters, A.F.; Maschmeyer, T. Interactions of plasmonic silver nanoparticles with high energy sites on multi-faceted rutile $\mathrm{TiO}_{2}$ photoanodes. ChemCatChem 2020, 12, 469-477. [CrossRef]

71. Li, K.; Peng, T.Y.; Ying, Z.H.; Song, S.S.; Zhang, J. Ag-loading on brookite $\mathrm{TiO}_{2}$ quasi nanocubes with exposed $\{210\}$ and $\{001\}$ facets: Activity and selectivity of $\mathrm{CO}_{2}$ photoreduction to $\mathrm{CO} / \mathrm{CH}_{4}$. Appl. Catal. B Environ. 2016, 180, 130-138. [CrossRef]

72. Bryl, R.; Olewicz, T.; de Bocarme, T.V.; Kruse, N. Thermal faceting of clean and oxygen-covered Ir nanocrystals. J. Phys. Chem. C 2011, 115, 2761-2768. [CrossRef]

73. Yu, Z.Z.; Zhan, B.W.; Ge, B.H.; Zhu, Y.T.; Dai, Y.; Zhou, G.J.; Yu, F.P.; Wang, P.; Huang, B.B.; Zhan, J. Synthesis of high efficient and stable plasmonic photocatalyst $\mathrm{Ag} / \mathrm{AgNbO}_{3}$ with specific exposed crystal-facets and intimate heterogeneous interface via combustion route. Appl. Surf. Sci. 2019, 488, 485-493. [CrossRef]

74. Hou, C.T.; Liu, W.L.; Zhu, J.M. Synthesis of $\mathrm{NaOH}$-modified $\mathrm{TiOF}_{2}$ and its enhanced visible light photocatalytic performance on RhB. Catalysts 2017, 7, 243. [CrossRef]

75. Li, W.Z.; Kovarik, L.; Mei, D.H.; Liu, J.; Wang, Y.; Peden, C.H.F. Stable platinum nanoparticles on specific $\mathrm{MgAl}_{2} \mathrm{O}_{4}$ spinel facets at high temperatures in oxidizing atmospheres. Nat. Commun. 2013, 4, 2481. [CrossRef] [PubMed]

76. Li, J.Y.; Dong, X.A.; Sun, Y.J.; Cen, W.L.; Dong, F. Facet-dependent interfacial charge separation and transfer in plasmonic photocatalysts. Appl. Catal. B Environ. 2018, 226, 269-277. [CrossRef]

77. Zhang, L.; Wang, W.Z.; Sun, S.M.; Jiang, D.; Gao, E.P. Selective transport of electron and hole among \{001\} and $\{110\}$ facets of $\mathrm{BiOCl}$ for pure water splitting. Appl. Catal. B Environ. 2015, 162, 470-474. [CrossRef]

78. Dong, F.; Xiong, T.; Yan, S.; Wang, H.Q.; Sun, Y.J.; Zhang, Y.X.; Huang, H.W.; Wu, Z.B. Facets and defects cooperatively promote visible light plasmonic photocatalysis with Bi nanowires@BiOCl nanosheets. J. Catal. 2016, 344, 401-410. [CrossRef]

79. Warmuth, L.; Ritschel, C.; Feldmann, C. Facet-, composition- and wavelength-dependent photocatalysis of $\mathrm{Ag}_{2} \mathrm{MoO}_{4}$. RSC Adv. 2020, 10, 18377-18383. [CrossRef]

80. Li, R.G.; Han, H.X.; Zhang, F.X.; Wang, D.G.; Li, C. Highly efficient photocatalysts constructed by rational assembly of dual-cocatalysts separately on different facets of $\mathrm{BiVO}_{4}$. Energy Environ. Sci. 2014, 7, 1369-1376. [CrossRef]

81. Wang, X.W.; Wang, W.Y.; Miao, Y.Q.; Feng, G.; Zhang, R.B. Facet-selective photodeposition of gold nanoparticles on faceted $\mathrm{ZnO}$ crystals for visible light photocatalysis. J. Colloid Interf. Sci. 2016, 475, 112-118. [CrossRef] [PubMed]

82. Wang, B.; Liu, M.C.; Zhou, Z.H.; Guo, L.J. Surface activation of faceted photocatalyst: When metal cocatalyst determines the nature of the facets. Adv. Sci. 2015, 2, 1500153. [CrossRef] [PubMed]

83. Janczarek, M.; Wei, Z.; Endo, M.; Ohtani, B.; Kowalska, E. Silver- and copper-modified decahedral anatase tiania particles as visible light-responsive plasmonic photocatalyst. J. Photonics Energy 2017, 7, 1-16.

84. Wei, Z.; Endo, M.; Wang, K.; Charbit, E.; Markowska-Szczupak, A.; Ohtani, B.; Kowalska, E. Noble metal-modified octahedral anatase titania particles with enhanced activity for decomposition of chemical and microbiological pollutants. Chem. Eng. J. 2017, 318, 121-134. [CrossRef]

85. Wei, Z.; Rosa, L.; Wang, K.; Endo, M.; Juodkazi, S.; Ohtani, B.; Kowalska, E. Size-controlled gold nanoparticles on octahedral anatase particles as efficient plasmonic photocatalyst. Appl. Catal. B Environ. 2017, 206, 393-405. [CrossRef]

86. Wei, Z.; Janczarek, M.; Endo, M.; Wang, K.L.; Balcytis, A.; Nitta, A.; Mendez-Medrano, M.G.; Colbeau-Justin, C.; Juodkazis, S.; Ohtani, B.; et al. Noble metal-modified faceted anatase titania photocatalysts: Octahedron versus decahedron. Appl. Catal. B Environ. 2018, 237, 574-587. [CrossRef]

87. Endo, M.; Janczarek, M.; Wei, Z.; Wang, K.; Markowska-Szczupak, A.; Ohtani, B.; Kowalska, E. Bactericidal properties of plasmonic photocatalysts composed of noble-metal nanoparticles on faceted ana-tase titania. J. Nanosci. Nanotechnol. 2019, 19, 442-452. [CrossRef] 
88. Endo-Kimura, M.; Kowalska, E. Plasmonic photocatalysts for microbiological applications. Catalysts 2020, 10, 824. [CrossRef]

89. Mao, J.; Ye, L.Q.; Li, K.; Zhang, X.H.; Liu, J.Y.; Peng, T.Y.; Zan, L. Pt-loading reverses the photocatalytic activity order of anatase $\mathrm{TiO}_{2}\{001\}$ and $\{010\}$ facets for photoreduction of $\mathrm{CO}_{2}$ to $\mathrm{CH}_{4}$. Appl. Catal. B Environ. 2014, 144, 855-862. [CrossRef]

90. Xiong, Z.; Lei, Z.; Chen, X.X.; Gong, B.G.; Zhao, Y.C.; Zhang, J.Y.; Zheng, C.G.; Wu, J.C.S. CO 2 photocatalytic reduction over Pt deposited $\mathrm{TiO}_{2}$ nanocrystals with coexposed $\{101\}$ and $\{001\}$ facets: Effect of deposition method and Pt precursors. Catal. Commun. 2017, 96, 1-5. [CrossRef]

91. Kobayashi, K.; Takashima, M.; Takase, M.; Ohtani, B. Mechanistic study on facet-dependent deposition of metal nanoparticles on decahedral-shaped anatase titania photocatalyst particles. Catalysts 2018, 8, 542. [CrossRef]

92. Zielinska-Jurek, A.; Wei, Z.S.; Janczarek, M.; Wysocka, I.; Kowalska, E. Size-controlled synthesis of Pt particles on $\mathrm{TiO}_{2}$ surface: Physicochemical characteristic and photocatalytic activity. Catalysts 2019, 9, 940. [CrossRef]

93. Chen, Q.; Chen, X.J.; Fang, M.L.; Chen, J.Y.; Li, Y.J.; Xie, Z.X.; Kuang, Q.; Zheng, L.S. Photo-induced Au-Pd alloying at $\mathrm{TiO}_{2}\{101\}$ facets enables robust $\mathrm{CO}_{2}$ photocatalytic reduction into hydrocarbon fuels. J. Mater. Chem. A 2019, 7, 1334-1340. [CrossRef]

94. Bian, J.; Qu, Y.; Zhang, X.L.; Sun, N.; Tang, D.Y.; Jing, L.Q. Dimension-matched plasmonic $\mathrm{Au} / \mathrm{TiO}_{2} / \mathrm{BiVO}_{4}$ nanocomposites as efficient wide-visible-light photocatalysts to convert $\mathrm{CO}_{2}$ and mechanistic insights. J. Mater. Chem. A 2018, 6, 11838-11845. [CrossRef]

95. Verbruggen, S.W.; Keulemans, M.; Goris, B.; Blommaerts, N.; Bals, S.; Martens, J.A.; Lenaerts, S. Plasmonic 'rainbow' photocatalyst with broadband solar light response for environmental applications. Appl. Catal. B Environ. 2016, 188, 147-153. [CrossRef]

96. Mendez-Medrano, M.G.; Kowalska, E.; Lehoux, A.; Herissan, A.; Ohtani, B.; Bahena, D.; Briois, V.; Colbeau-Justin, C.; Rodriguez-Lopez, J.; Remita, H. Surface modification of $\mathrm{TiO}_{2}$ with Ag nanoparticles and $\mathrm{CuO}$ nanoclusters for applications in photocatalysis. J. Phys. Chem. C 2016, 120, 5143-5154. [CrossRef]

97. Kowalska, E.; Janczarek, M.; Rosa, L.; Juodkazi, S.; Ohtani, B. Mono- and bi-metallic plasmonic photocatalysts for degradation of organic compounds under UV and visible light irradiation. Catal. Today 2014, 230, 131-137. [CrossRef]

98. Malankowska, A.; Kobylanski, M.P.; Mikolajczyk, A.; Cavdar, O.; Nowaczyk, G.; Jarek, M.; Lisowski, W.; Michalska, M.; Kowalska, E.; Ohtani, B.; et al. $\mathrm{TiO}_{2}$ and $\mathrm{NaTaO}_{3}$ decorated by trimetallic $\mathrm{Au} / \mathrm{Pd} / \mathrm{Pt}$ core-shell nanoparticles as efficient photocatalysts: Experimental and computational studies. ACS Sustain. Chem. Eng. 2018, 6, 16665-16682. [CrossRef]

99. DeSario, P.A.; Pietron, J.J.; Brintlinger, T.H.; McEntee, M.; Parker, J.F.; Baturina, O.; Stroud, R.M.; Rolison, D.R. Oxidation-stable plasmonic copper nanoparticles in photocatalytic $\mathrm{TiO}_{2}$ nanoarchitectures. Nanoscale 2017, 9 , 11720-11729. [CrossRef]

100. DeSario, P.A.; Pietron, J.J.; DeVantier, D.E.; Brintlinger, T.H.; Stroud, R.M.; Rolison, D.R. Plasmonic enhancement of visible-light water splitting with $\mathrm{Au}-\mathrm{TiO}_{2}$ composite aerogels. Nanoscale 2013, 5, 8073-8083. [CrossRef]

101. Panayotov, D.A.; DeSario, P.A.; Pietron, J.J.; Brintlinger, T.H.; Szymczak, L.C.; Rolison, D.R.; Morris, J.R. Ultraviolet and visible photochemistry of methanol at 3D mesoporous networks: $\mathrm{TiO}_{2}$ and $\mathrm{Au}-\mathrm{TiO}_{2}$. J. Phys. Chem. C 2013, 117, 15035-15049. [CrossRef]

102. Horiguchi, Y.; Kanda, T.; Torigoe, K.; Sakai, H.; Abe, M. Preparation of gold/silver/titania trilayered nanorods and their photocatalytic activities. Langmuir 2014, 30, 922-928. [CrossRef] [PubMed]

103. Bielan, Z.; Kowalska, E.; Dudziak, S.; Wang, K.; Ohtani, B.; Zielinska-Jurek, A. Mono- and bimetallic (Pt/Cu) titanium(IV) oxide core-shell photocatalysts with UV/Vis light activity and magnetic separability. Catal. Today 2020, in press. [CrossRef]

104. Bielan, Z.; Sulowska, A.; Dudziak, S.; Siuzdak, K.; Ryl, J.; Zielinska-Jurek, A. Defective $\mathrm{TiO}_{2}$ core-shell magnetic photocatalyst modified with plasmonic nanoparticles for visible light-induced photocatalytic activity. Catalysts 2020, 10, 672. [CrossRef]

105. Zheng, S.; Wei, Z.; Yoshiiri, K.; Braumuller, M.; Ohtani, B.; Rau, S.; Kowalska, E. Titania modification with ruthenium(II) complex and gold nanoparticles for photocatalytic degradation of organic compounds. Photochem. Photobiol. Sci. 2016, 15, 69-79. [CrossRef] 
106. Zheng, S.Z.; Wang, K.L.; Wei, Z.S.; Yoshiiri, K.; Braumuller, M.; Rau, S.; Ohtani, B.; Kowalska, E. Mono- and dual-modified titania with a ruthenium(II) complex and silver nanoparticles for photocatalytic degradation of organic compounds. J. Adv. Oxid. Technol. 2016, 19, 208-217. [CrossRef]

107. Kowalska, E.; Yoshiiri, K.; Wei, Z.; Zheng, S.; Kastl, E.; Remita, H.; Ohtani, B.; Rau, S. Hybrid photocatalysts composed of titania modified with plasmonic nanoparticles and ruthenium complexes for decomposition of organic compounds. Appl. Catal. B Environ. 2015, 178, 133-143. [CrossRef]

108. Jiang, L.M.; Zhou, G.; Mi, J.; Wu, Z.Y. Fabrication of visible-light-driven one-dimensional anatase $\mathrm{TiO}_{2} / \mathrm{Ag}$ heterojunction plasmonic photocatalyst. Catal. Commun. 2012, 24, 48-51. [CrossRef]

109. Tahir, M.; Tahir, B.; Amin, N.A.S. Synergistic effect in plasmonic Au/Ag alloy NPs co-coated $\mathrm{TiO}_{2} \mathrm{NWs}$ toward visible-light enhanced $\mathrm{CO}_{2}$ photoreduction to fuels. Appl. Catal. B Environ. 2017, 204, 548-560. [CrossRef]

110. Nasir, M.S.; Yang, G.R.; Ayub, I.; Wang, S.L.; Yan, W. In situ decoration of g- $\mathrm{C}_{3} \mathrm{~N}_{4}$ quantum dots on 1D branched $\mathrm{TiO}_{2}$ loaded with plasmonic Au nanoparticles and improved the photocatalytic hydrogen evolution activity. Appl. Surf. Sci. 2020, 519, 146208. [CrossRef]

111. Zheng, F.; Zhu, Z.T. Preparation of the $\mathrm{Au} @ \mathrm{TiO}_{2}$ nanofibers by one-step electrospinning for the composite photoanode of dye-sensitized solar cells. Mater. Chem. Phys. 2018, 208, 35-40. [CrossRef]

112. Khatun, F.; Abd Aziz, A.; Sim, L.C.; Monir, M.U. Plasmonic enhanced Au decorated $\mathrm{TiO}_{2}$ nanotube arrays as a visible light active catalyst towards photocatalytic $\mathrm{CO}_{2}$ conversion to $\mathrm{CH}_{4}$. J. Environ. Chem. Eng. 2019, 7, 103233. [CrossRef]

113. Fu, N.Q.; Jiang, X.Z.; Chen, D.C.; Duan, Y.D.; Zhang, G.G.; Chang, M.L.; Fang, Y.Y.; Lin, Y. Au/TiO 2 nanotube array based multi-hierarchical architecture for highly efficient dye-sensitized solar cells. J. Power Sources 2019, 439, 227076. [CrossRef]

114. Wang, S.; Zhang, Z.; Huo, W.; Zhu, K.; Zhang, X.; Zhou, X.; Fang, F.; Xie, Z.G.; Jiang, J. Preferentially oriented $\mathrm{Ag}-\mathrm{TiO}_{2}$ nanotube array film: An efficient visible-light-driven photocatalyst. J. Hazard. Mater. 2020, 399, 123016. [CrossRef]

115. Mazierski, P.; Malankowska, A.; Kobylanski, M.; Diak, M.; Kozak, M.; Winiarski, M.J.; Klimczuk, T.; Lisowski, W.; Nowaczyk, G.; Zaleska-Medynska, A. Photocatalytically active $\mathrm{TiO}_{2} / \mathrm{Ag}_{2} \mathrm{O}$ nanotube arrays interlaced with silver nanoparticles obtained from the one-step anodic oxidation of Ti-Ag alloys. ACS Catal. 2017, 7, 2753-2764. [CrossRef]

116. Wei, Z.S.; Endo-Kimura, M.; Wang, K.L.; Colbeau-Justin, C.; Kowalska, E. Influence of semiconductor morphology on photocatalytic activity of plasmonic photocatalysts: Titanate nanowires and octahedral anatase nanoparticles. Nanomaterials 2019, 9, 1447. [CrossRef]

117. Bian, Z.F.; Tachikawa, T.; Zhang, P.; Fujitsuka, M.; Majima, T. Au/ $\mathrm{TiO}_{2}$ superstructure-based plasmonic photocatalysts exhibiting efficient charge separation and unprecedented activity. J. Am. Chem. Soc. 2014, 136, 458-465. [CrossRef] [PubMed]

118. Yan, J.Q.; Wu, G.J.; Dai, W.L.; Guan, N.J.; Li, L.D. Synthetic design of gold nanoparticles on anatase $\mathrm{TiO}_{2}$ $\{001\}$ for enhanced visible light harvesting. ACS Sustain. Chem. Eng. 2014, 2, 1940-1946. [CrossRef]

119. Kumar, N.S.; Asif, M.; Reddy, T.R.K.; Shanmugam, G.; Ajbar, A. Silver quantum dot decorated $2 \mathrm{D}_{-} \mathrm{SnO}_{2}$ nanoflakes for photocatalytic degradation of the water pollutant Rhodamine B. Nanomaterials 2019, 9, 1536. [CrossRef]

120. Li, H.X.; Li, Z.D.; Yu, Y.H.; Ma, Y.J.; Yang, W.G.; Wang, F.; Yin, X.; Wang, X.D. Surface-plasmon-resonance-enhanced photoelectrochemical water splitting from Au-nanoparticle-decorated 3D $\mathrm{TiO}_{2}$ nanorod architectures. J. Phys. Chem. C 2017, 121, 12071-12079. [CrossRef]

121. Song, C.K.; Baek, J.; Kim, T.Y.; Yu, S.; Han, J.W.; Yi, J. Exploring crystal phase and morphology in the $\mathrm{TiO}_{2}$ supporting materials used for visible-light driven plasmonic photocatalyst. Appl. Catal. B Environ. 2016, 198, 91-99. [CrossRef]

122. Mendez-Medrano, M.G.; Kowalska, E.; Endo, M.; Wang, K.; Bahena, D.; Rodriguez-Lopez, J.L.; Remita, H. Inhibition of fungal growth using modified $\mathrm{TiO}_{2}$ with core@shell structure of Ag@CuO clusters. ACS Appl. Bio Mater. 2019, 2, 5626-5633. [CrossRef]

123. Raja-Mogan, T.; Ohtani, B.; Kowalska, E. Photonic crystals for plasmonic photocatalysis. Catalysts 2020, 10, 827. [CrossRef] 
124. Lu, Y.; Yu, H.T.; Chen, S.; Quan, X.; Zhao, H.M. Integrating plasmonic nanoparticles with $\mathrm{TiO}_{2}$ photonic crystal for enhancement of visible-light-driven photocatalysis. Environ. Sci. Technol. 2012, 46, 1724-1730. [CrossRef]

125. Zhang, X.; Liu, Y.; Lee, S.T.; Yang, S.H.; Kang, Z.H. Coupling surface plasmon resonance of gold nanoparticles with slow-photon-effect of $\mathrm{TiO}_{2}$ photonic crystals for synergistically enhanced photoelectrochemical water splitting. Energy Environ. Sci. 2014, 7, 1409-1419. [CrossRef]

126. Zhang, S.S.; Peng, B.Y.; Yang, S.Y.; Wang, H.G.; Yu, H.; Fang, Y.P.; Peng, F. Non-noble metal copper nanoparticles-decorated $\mathrm{TiO}_{2}$ nanotube arrays with plasmon-enhanced photocatalytic hydrogen evolution under visible light. Int. J. Hydrogen Energy 2015, 40, 303-310. [CrossRef]

127. Ebessen, T.W.; Lezec, H.J.; Ghaemi, H.F.; Thio, T.; Wolff, P.A. Extraordinary optical transmission through sub-wavelength hole arrays. Nature 1998, 391, 667669. [CrossRef]

128. Rodrigo, S.G.; de Leon-Perez, F.; Martin-Moreno, L. Extraordinary optical transmission: Fundamentals and applications. Proc. IEEE 2016, 104, 2288-2306. [CrossRef]

129. Boppella, R.; Kochuveedu, S.T.; Kim, H.; Jeong, M.J.; Mota, F.M.; Park, J.H.; Kim, D.H. Plasmon-sensitized graphene $/ \mathrm{TiO}_{2}$ inverse opal nanostructures with enhanced charge collection efficiency for water splitting. ACS Appl. Mater. Interfaces 2017, 9, 7075-7083. [CrossRef]

130. Kakekhani, A.; Ismail-Beigi, S.; Altman, E.I. Ferroelectrics: A pathway to switchable surface chemistry and catalysis. Surf. Sci. 2016, 650, 302-316. [CrossRef]

131. Su, R.; Shen, Y.J.; Li, L.L.; Zhang, D.W.; Yang, G.; Gao, C.B.; Yang, Y.D. Silver-modified nnosized frroelectrics as a nvel potocatalyst. Small 2015, 11, 202-207. [CrossRef] [PubMed]

132. Wu, M.; Ding, T.; Wang, Y.; Zhao, W.; Xian, H.; Tian, Y.; Zhang, T.; Li, X. Rational construction of plasmon $\mathrm{Au}$ assisted ferroelectric-BaTiO$/ \mathrm{Au} / \mathrm{g}-\mathrm{C}_{3} \mathrm{~N}_{4} \mathrm{Z}$-scheme system for efficient photocatalysis. Catal. Today 2019. [CrossRef]

133. Cui, Y.F.; Sun, H.H.; Shen, G.D.; Jing, P.P.; Pu, Y.P. Effect of dual-cocatalyst surface modification on photodegradation activity, pathway, and mechanisms with highly efficient $\mathrm{Ag} / \mathrm{BaTiO} / \mathrm{MnO}_{\mathrm{x}}$. Langmuir 2020, 36, 498-509. [CrossRef] [PubMed]

134. Lan, J.Y.; Zhou, X.M.; Liu, G.; Yu, J.G.; Zhang, J.C.; Zhi, L.J.; Nie, G.J. Enhancing photocatalytic activity of one-dimensional $\mathrm{KNbO} 3$ nanowires by Au nanoparticles under ultraviolet and visible-light. Nanoscale 2011, 3, 5161-5167. [CrossRef]

135. Zhang, X.G.; Wang, B.; Wang, X.Z.; Xiao, X.H.; Dai, Z.G.; Wu, W.; Zheng, J.F.; Ren, F.; Jiang, C.Z. Preparation of $\mathrm{M} @ B i F e O_{3}$ nanocomposites $(\mathrm{M}=\mathrm{Ag}, \mathrm{Au})$ bowl arrays with enhanced visible light photocatalytic activity. J. Am. Ceram. Soc. 2015, 98, 2255-2263. [CrossRef]

136. Cui, Y.F.; Briscoe, J.; Dunn, S. Effect of ferroelectricity on solar-light-driven photocatalytic activity of $\mathrm{BaTiO}_{3}$-Influence on the carrier separation and stern layer formation. Chem. Mater. 2013, 25, 4215-4223. [CrossRef]

137. Cui, Y.F.; Goldup, S.M.; Dunn, S. Photodegradation of Rhodamine B over Ag modified ferroelectric $\mathrm{BaTiO}_{3}$ under simulated solar light: Pathways and mechanism. RSC Adv. 2015, 5, 30372-30379. [CrossRef]

138. Chao, C.Y.; Zhou, Y.P.; Han, T.L.; Yang, Y.Y.; Wei, J.Y.; Li, H.; He, W.W. Ferroelectric polarization-enhanced photocatalytic properties and photo-induced charge carrier behavior of $\mathrm{Au} / \mathrm{BaTiO}_{3}$. J. Alloy. Compd. 2020, 825,154060 . [CrossRef]

139. Kumar, V.; O’Donnell, S.; Zoellner, B.; Martinez, J.; Wang, G.; Maggard, P.A. Interfacing plasmonic nanoparticles with ferroelectrics for hot-carrier-driven photocatalysis: Impact of Schottky barrier height. ACS Appl. Energy Mater. 2019, 2, 7690-7699. [CrossRef]

(C) 2020 by the authors. Licensee MDPI, Basel, Switzerland. This article is an open access article distributed under the terms and conditions of the Creative Commons Attribution (CC BY) license (http://creativecommons.org/licenses/by/4.0/). 